\title{
Uma nova estratégia para o cálculo de afinidades eletrônicas
}

Dissertação apresentada ao Instituto de Química de São Carlos, Universidade de São Paulo, como parte dos requisitos para obtenção do título de Mestre em Ciências.

Área de Concentração: Físico-Química

Orientador: Prof. Dr. Albérico Borges Ferreira da Silva

\section{Exemplar revisado}

$O$ exemplar original encontra-se em acervo reservado na Biblioteca do IQSC-USP

São Carlos 
Aos meus avós, Maria e Eliel. Que abdicaram de muitas coisas para custear uma educação de qualidade para mim e meus irmãos. Sem seu amor e cuidados eu nunca estaria aqui.

Aos meus pais, Abrã̃o e Daniela. Pelo amor e por terem feito tudo que estava ao alcance.

Aos meus irmãos Abraão Jr. e Brenda. "What if i'm far from home? Oh, brother $i$ will hear you call. What if $i$ lose it all? Oh, sister $i$ will help you out. Oh, if the sky comes falling down for you, there's nothing in this world $i$ wouldn't do.” Porque os laços de sangue são mais fortes que tudo. 


\section{Agradecimentos}

- À toda minha família, por sempre acreditar na minha capacidade.

- À Sueny, Dulce e família, por todo apoio, amor e carinho que me deram desde de que eu cheguei em São Carlos.

- Ao professor Dr. Albérico Borges Ferreira da Silva, meu orientador, pela oportunidade de orientação e ensinamentos.

- À professora Dra. Rosenira Serpa da Cruz, pelo apoio e orientação durante minha iniciação científica na Universidade Estadual de Santa Cruz, e por ter me incentivado a fazer mestrado fora de casa.

- Aos meus amigos e colegas do grupo de pesquisa, em especial ao Celião, Rommel e Ana Cristina, pelo companheirismo e ajuda nas horas de precisão.

- Ao professor Dr. Ricardo Celeste pelos ensinamentos em programas de química computacional.

- Aos funcionários da pós-graduação do IQSC-USP e do prédio de química estrutural pela simpatia e boa vontade em nos ajudar.

- À CAPES, pela bolsa concedida.

- Ao estado de São Paulo, por ter me acolhido e proporcionado pessoas e experiências incríveis na minha vida. 
"What is the difference between a man and a parasite? A man builds. A parasite asks 'Where is my share?' A man creates. A parasite says, 'What will the neighbors think?' A man invents. A parasite says, 'Watch out, or you might tread on the toes of God...”

“A man chooses, a slave obeys.”

- Andrew Ryan, Bioshock. 


\section{RESUMO}

A afinidade eletrônica (AE) é uma importante propriedade de átomos e moléculas, sendo definida como a diferença de energia entre a espécie neutra e seu respectivo íon negativo. Uma vez que a AE é uma fração muito pequena da energia eletrônica total das espécies neutra e aniônica, é necessário que tais energias sejam determinadas com elevado grau de precisão. A receita utilizada para o cálculo teórico acurado da $\mathrm{AE}$ atômica e molecular baseia-se na escolha de um conjunto adequado de funções de base juntamente com o emprego de teorias com altos níveis de correlação eletrônica. Durante o cálculo, o mesmo conjunto de base é utilizado para descrever o elemento neutro e seu respectivo ânion. Geralmente, os conjuntos de base para descrever propriedades de ânions possuem seus expoentes otimizados em ambiente neutro, e sua difusibilidade é conferida pela adição de funções difusas para cada valor de momento angular, $l$. A ideia deste trabalho está no desenvolvimento de conjuntos de base otimizados exclusivamente em ambiente aniônico para cálculos precisos de afinidade eletrônica. Deste modo, foram escolhidos os átomos para serem estudados: B, C, O e F. Os conjuntos de base foram gerados pelo Método da Coordenada Geradora Hartree-Fock, empregando a técnica da Discretização Integral Polinomial para a solução das integrais do problema. Os conjuntos de base obtidos são compostos por (18s13p) primitivas que foram contraídos para [7s6p] via esquema de contração geral proposto por Raffenetti. Os conjuntos contraídos foram polarizados para $4 d 3 f 2 g$ e $4 d 3 f 2 g 1 h$, sendo os expoentes otimizados em ambiente CISD através do método SIMPLEX. Avaliaram-se as funções de base no cálculo de afinidades eletrônicas, tendo seus resultados comparados aos obtidos utilizando as bases aug-cc-pVQZ e aug-cc-pV5Z. A análise dos resultados demonstrou que os conjuntos de base difusos, gerados neste trabalho, reproduzem de maneira satisfatória as afinidades eletrônicas em relação ao valor experimental. Os conjuntos difusos polarizados para $4 d 3 f 2 g l h$ apresentaram eficiência superior aos conjuntos aug-cc-pVQZ e, em alguns casos, aos conjuntos aug-cc-pV5Z que são consideravelmente maiores.

Palavras-chave: Afinidade Eletrônica; Conjuntos de Base; Método da Coordenada Geradora; Discretização Integral Polinomial; Funções Difusas; 


\begin{abstract}
The electron affinity (EA) is an important property of atoms and molecules defined as the energy difference between the neutral species and its negative ion. Since the EA is a very small fraction of the total electronic energy of anionic and neutral species, one must determine these energies with high accuracy. The recipe used to calculate accurate atomic and molecular EAs is based on the choice of an adequate basis set and the use of high level of electron correlation calculations. In the computation of EAs, the same basis set is used to describe both neutral and negatively charged species. In general, the basis sets designed to describe anionic properties have their exponents optimized in neutral environment, and its diffuseness is acquired through the addition of diffuse functions for each angular momentum. The main idea of this work is to develop basis sets optimized exclusively in anionic environment that would be applied in accurate calculations of electron affinity. Thus, here follows the chosen atoms to be studied: B, C, O and F. The basis sets were generated by the Generator Coordinate HartreeFock Method through the Polynomial Integral Discretization Method. Basis sets were obtained containing $(18 \mathrm{~s} 13 p)$ primitives that were contracted to [7s6p] via Raffenetti's general contraction scheme. The contracted basis sets were polarized to $4 \mathrm{~d} 3 \mathrm{f} 2 \mathrm{~g}$ and $4 \mathrm{~d} 3 \mathrm{f} 2 \mathrm{~g} 1 \mathrm{~h}$, and the exponents of polarization were optimized in a CISD environment through the Simplex algorithm. The basis sets quality was evaluated through the calculation of the electron affinities. The results were compared to those obtained by using the aug-cc-pVQZ and augcc-pV5Z basis-sets. The calculation showed that our diffuse basis sets reproduce satisfactorily the electron affinities when compared to the experimental data. The diffuse basis sets polarized to $4 \mathrm{~d} 3 \mathrm{f} 2 \mathrm{~g} 1 \mathrm{~h}$ showed to be more efficient than the aug-cc-pVQZ basis sets and in some cases also better than the aug-cc-pV5Z basis sets that are considerably larger.
\end{abstract}

Keywords: Electron Affinity; Basis Sets; Method of Generator Coordinate; Polynomial Integral Discretization; Diffuse Functions; 


\section{LISTA DE ILUSTRAÇÕES}

Figura 1 - Diagrama qualitativo das superfícies de energia potencial para uma molécula $\mathrm{M}$ e seu respectivo ânion $\mathrm{M}^{-}$.

Figura 2 - Esquema de cálculos para as afinidades eletrônicas. .45

Figura 3 - Comparação entre as afinidades eletrônicas relativas (\%) para os conjuntos 6ZMCG-ION4d3f2g, 6ZMCG-ION4d3f2g1h, aug-cc-pVQZ e aug-cc-pV5Z. .49

Figura 4 - Comparação entre as afinidades eletrônicas relativas (\%) para os conjuntos 6ZMCG-ION4d3f2g e aug-cc-pVQZ .51 


\section{LISTA DE TABELAS}

Tabela 1: Energias Hartree-Fock obtidas com o conjunto de primitivas para os átomos neutros e seus ânions

Tabela 2: Resultados para afinidades eletrônicas calculadas pelo método Hartree-Fock utilizando os conjuntos de polarização $4 d 3 f 2 g$

Tabela 3: Resultados para afinidades eletrônicas calculadas pelo método Hartree-Fock utilizando os conjuntos de polarização $4 d 3 f 2 g l h$

Tabela 4: Resultados para afinidades eletrônicas calculadas em nível QCISD(T) utilizando os conjuntos de polarização $4 d 3 f 2 g$.....

Tabela 5: Resultados para afinidades eletrônicas calculadas em nível QCISD(T) utilizando os conjuntos de polarização $4 d 3 f 2 g h$.

Tabela 6: Comparativo entre as AEs obtidas com as bases 6ZMCG-ION (4d3f2g e 4d3f2g1h), aug-cc-pVQZ e aug-cc-pV5Z.

Tabela 7: Resultados para afinidades eletrônicas moleculares calculadas em nível QCISD utilizando os conjuntos de polarização $4 d 3 f 2 g$ e aug-cc-pVQZ 


\title{
LISTA DE SIGLAS
}

\author{
AE Afinidade Eletrônica \\ VDE Vertical Detachment Energy \\ HF Hartree-Fock \\ RHF Restricted Hartree-Fock \\ STF Slater Type Function \\ GTF Gaussian Type Function \\ MCG Método da Coordenada Geradora \\ CG Coordenada Geradora \\ GW Griffin-Wheeler
}

GH-HF Griffin-Wheeler-Hartree-Fock

DV Discretização Variacional

DI Discretização Integral

DIP Discretização Integral Polinomial

CI Configuration Interaction

CC Coupled Cluster

MPPT Møller-Plesset Perturbation Theory 


\section{SUMÁRIO}

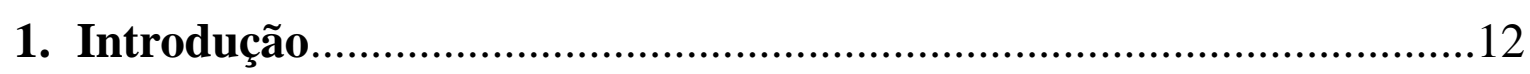

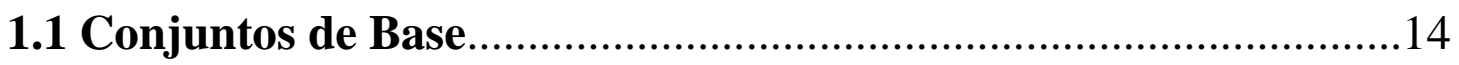

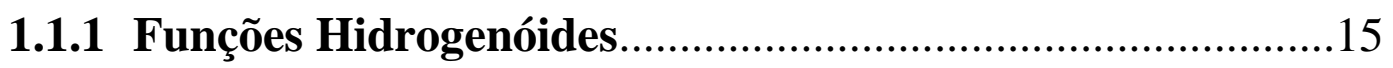

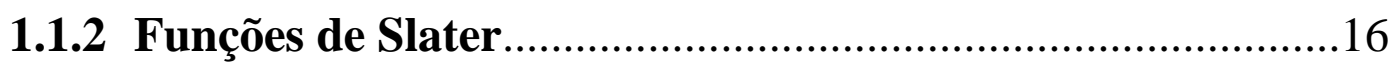

1.1.3 Funções Gaussianas............................................................17

1.2 Qualidade dos Conjuntos de Base..................................................18

1.2.1 O Conjunto de Base Mínima..................................................19

1.2.2 Base Double-Zeta e Base Estendida.......................................19

1.2.3 Conjuntos do tipo Split-Valence ……………...........................19

1.3 Determinação dos Expoentes: O Método Variacional....................19

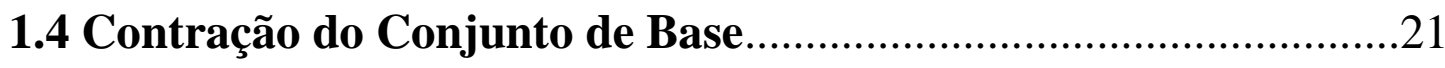

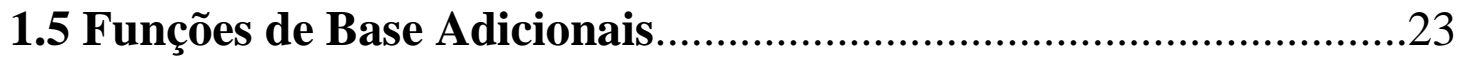

1.5.1 Funções de Polarização.........................................................23

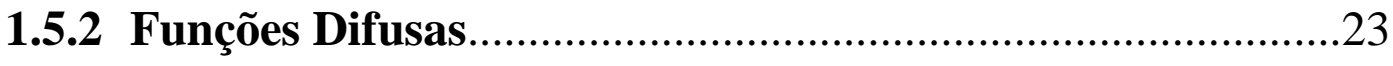

1.6 Os Conjuntos de Base aug-cc-pVQZ e aug-cc-pV5Z...................24

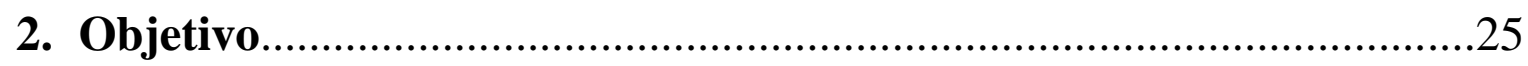

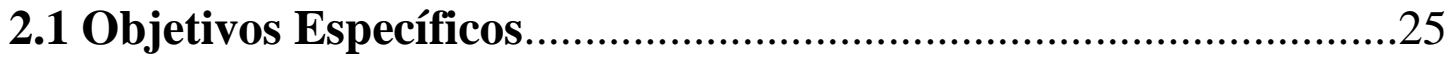

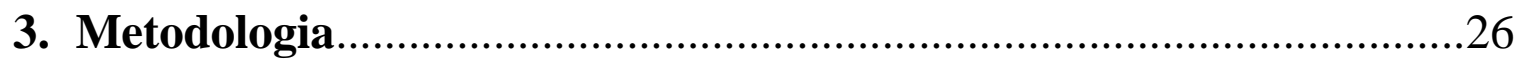

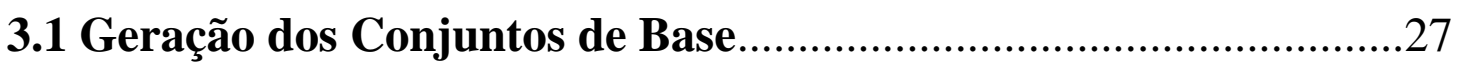

3.1.1 O Método Hartree-Fock......................................................27

3.1.2 O Método da Coordenada Geradora Hartree-Fock.............34

3.1.3 A Discretização Integral e a Troca de Rótulos.......................37

3.1.4 A Discretização Integral Polinomial.......................................39

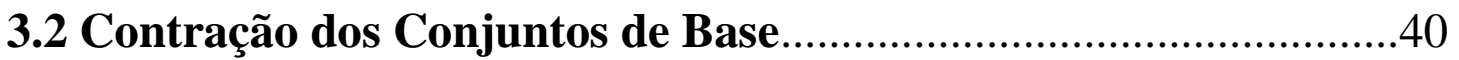

3.3 Polarização dos Conjuntos de Base...............................................40

3.4 Avaliação dos Conjuntos de Base: Cálculo das Afinidades Eletrônicas. 
3.4.1 Afinidade Eletrônica Atômica................................................4

3.4.2 Afinidade Eletrônica Molecular...........................................42

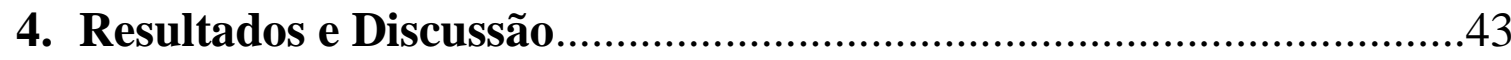

4.1 Geração dos Conjuntos de Base......................................................43

4.2 Cálculos de Afinidade Eletrônica Atômica......................................44

4.3 Cálculos de Afinidade Eletrônica Molecular..................................49

5. Conclusões e Perspectivas Futuras..................................................52

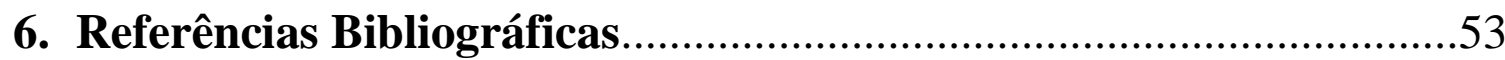

APÊNDICE 


\section{Introdução}

A afinidade eletrônica (AE) é uma importante propriedade de átomos e moléculas, sendo definida como a diferença de energia entre a espécie neutra e seu respectivo íon negativo. Uma $\mathrm{AE}$ positiva indica que o ânion é mais estável que seu análogo neutro, enquanto que o contrário é verdadeiro para uma $\mathrm{AE}$ negativa. A natureza é repleta de processos onde elétrons são transferidos entre corpos, aglomerados, partículas, sendo fundamental o conhecimento das afinidades eletrônicas no entendimento dos fenômenos. De fato, há muitas áreas da química, biologia ou ciência dos materiais, onde as propriedades de íons negativos são essenciais. A título de exemplo, AEs desempenham papel na química do fulereno [1], células solares [2, 3], semicondutores [4-6], sensores ópticos [7, 8], química de interfaces [9], etc. Pesquisas também enfatizam o papel da AE no entendimento de mecanismos de reação [10], estabilidade e papel biológico de compostos químicos [11].

A maioria dos experimentos utilizados na determinação da afinidade eletrônica envolve o uso de uma fonte de fótons de energia h $v$ (geralmente lasers) para separar o elétron da espécie carregada. A afinidade eletrônica, de uma perspectiva experimental, seria a energia mínima necessária para remover esse elétron. Um compêndio sobre métodos fotoelétricos, bem como um conjunto de 1101 resultados experimentais de AEs para átomos e moléculas podem ser encontrados no review de Rienstra-Kiracofe et al. [12], embora o NIST Chemistry Webbook [13] seja a fonte mais útil para aqueles que procuram um número maior de resultados.

Melhorias nas fontes a laser, detectores e outros componentes instrumentais permitiram o aumento na qualidade e precisão dos resultados experimentais. Todavia, ainda há uma série de complicações a cerca da determinação experimental de AEs. Normalmente, ânions de espécies cuja AE é positiva subsistem tempo o suficiente para interagir com processos físicos e químicos, permitindo que suas propriedades (i. e., afinidade eletrônica) sejam diretamente investigadas. Em contrapartida, ânions de átomos ou moléculas com AE negativa, salvo exceções, não existem durante um período de tempo mínimo necessário para serem estudados [12]. Além disso, a própria interpretação dos resultados experimentais para afinidades eletrônicas moleculares deve ser cuidadosamente avaliada. É importante esclarecer que em moléculas, a energia mínima necessária para retirar o elétron do ânion não equivale essencialmente à $\mathrm{AE}$, fazendo-se necessário a introdução de novos conceitos como afinidade eletrônica adiabática (AEA) e vertical detachment energy (VDE). Contudo, por questões de 
limitação experimental e simplicidade, para moléculas, a energia mínima necessária para retirar o elétron do ânion é aproximada como AE. As causas das dificuldades são compreensíveis, pois, ao contrário dos átomos, moléculas possuem estados eletrônicos, vibracionais e rotacionais, que são reflexos do maior grau de liberdade. Em consequência, à medida que as moléculas ou íons moleculares se tornam maiores e mais complexos, aumentase a dificuldade na estimativa confiável de suas AEs.

Apesar das limitações associados à determinação experimental de AEs, os pesquisadores hoje dispõem de diversas e complexas ferramentas para calculo teórico, capazes de caracterizar propriedades de espécies que nem ao menos foram sintetizadas e isoladas pelo homem. Cálculos $a b$ initio de afinidade eletrônica remontam entre o final da década de 50 e inicio da década de 60 com os trabalhos de Pekeris [14, 15], que estudava sistemas simples como $\mathrm{H}^{-}$e He cujos resultados altamente precisos levavam diversos tipos de correções (relativística, spin-orbita, Lamb shift). Desde então, AEs de sistemas complicados, ou cuja avaliação experimental é no mínimo questionável, vem sendo calculadas por diversos métodos computacionais. Por exemplo, é conhecido por experimentalistas de AE que provavelmente as energias relativamente altas dos LUMOs e os elevados momentos de dipolo das bases nucléicas tornam a determinação da AE desafiadora, e um grande esforço em pesquisa tem sido feito para calcula-las teoricamente [16-21]. Os super-halogenios, como o tetrafluoreto de boro, possuem AEs muito grandes (> 3.6) e também são estudados teoricamente por estarem fora do alcance da maioria dos sistemas a lasers comerciais [22]. Aqui estão outros exemplos de sistemas cuja $\mathrm{AE}$ foi calculada por propósitos particulares: chalconas [23], metais de transição [24], trimetilnaftalenos [25], complexos metálicos [26]. Pesquisas mais recentes podem ser encontrados nas referências [27-29].

Em detrimento do conceito relativamente simples, a determinação teórica de afinidades eletrônicas ainda permanece um desafio [16, 24, 29, 30]. Uma vez que a AE é uma fração muito pequena da energia eletrônica total das espécies neutra e aniônica, é necessário se determinar suas energias com elevada precisão (e. g., alguns décimos de elétron volt) [31]. Deste modo, não é uma surpresa que o método Hartree-Fock, método $a b$ initio que só correlaciona o movimento de elétrons com spin paralelo, falhe substancialmente ao ser empregado para computar AEs. Ademais, cálculos teóricos de AE exibem uma forte dependência com relação ao conjunto de funções de base utilizado, sendo de comum conhecimento que conjuntos de base com funções difusas são necessárias para a descrição 
apropriada da estrutura eletrônica de ânions atômicos e moleculares. A questão complica-se mais ainda, desde que grandes conjuntos de funções de polarização são exigidos para alcançar o limite do conjunto de base completo.

Na prática, a receita utilizada para o cálculo acurado de AE atômica e molecular é escolher um conjunto adequando de funções de base, com funções difusas e um grande grupo de funções de polarização, e emprega-lo em teorias com altos níveis de correlação eletrônica, para obter uma boa descrição da correlação de ambas as espécies neutra e aniônica. Geralmente, o conjunto de base utilizado possui funções otimizadas para a espécie neutra, e sua difusibilidade é conferida pela adição de funções difusas para cada valor de momento angular, $l$. Sabendo que o custo computacional depende exponencialmente do número de funções de base de cada conjunto, intui-se que a determinação teórica de AEs é uma tarefa custosa em termos computacionais, tornando-se proibitiva à medida que cresce a complexidade dos problemas estudados.

Neste trabalho, busca-se um novo recurso para o cálculo de afinidades eletrônicas atômicas e moleculares. Para tanto, propõe-se a geração, através do Método da Coordenada Geradora Hartree-Fock (MCG-HF), de um conjunto de funções de base otimizados em ambiente aniônico, que possua caráter difuso intrínseco. Deste modo, espera-se que esta nova base forneça uma descrição satisfatória da $\mathrm{AE}$ sem a necessidade de um número tão grande de funções no conjunto. Adicionalmente, Schaefer III e colaboradores [12] apontam que AEs precisas são obtidas apenas pelo uso do mesmo conjunto de base para descrever ambas as espécies neutra e aniônica. Sendo a nossa metodologia nova, é investigada a validade desta afirmação, onde as AEs serão calculadas por três maneiras diferentes: 1) ambas as espécies serão descritas pela base difusa (d-d), modo convencional; 2) ambas as espécies serão descritas por uma base "neutra" (n-n); e 3) a espécie neutra é descrita pela base neutra e seu respectivo ânion é descrito pela nossa base difusa (n-d). Isto posto, um conjunto de base otimizado em ambiente neutro também é gerado pelo MCG-HF especialmente para os testes dos casos 2) e 3).

\subsection{Conjuntos de Base}

A qualidade dos cálculos ab initio de estrutura eletrônica é definida pelo nível de teoria utilizado, que por sua vez depende de dois fatores: o método (HF, CI, CC, MPPT, etc) e o conjunto de base utilizado. Em álgebra, uma base é um conjunto de vetores linearmente 
independentes que definem o espaço no qual um problema é resolvido, por exemplo, com os vetores $\hat{\imath}, \hat{\jmath}, \hat{k}$ é possível descrever completamente o espaço cartesiano 3D. Em química quântica, o conjunto de base é um grupo de funções matemáticas de uma partícula, utilizado para desenhar orbitais atômicos e moleculares. Portanto, para um dado sistema, sua função orbital monoeletrônica $\Phi_{i}$ pode ser expandida como uma combinação linear de um conjunto completo de funções de base $\left\{\chi_{i}\right\}$. Dessa forma:

$$
\Phi_{i}=\sum_{u}^{t} C_{u i} \chi_{u}
$$

onde $C_{u i}$ são os coeficientes da expansão e $\chi_{u}$ as funções de base. A princípio, os orbitais são melhores descritos conforme se aumenta a flexibilidade da função monoeletrônica pelo acréscimo de termos na expansão. Felizmente, a descrição satisfatória de sistemas eletrônicos pode ser alcançada utilizando um conjunto finito de funções de base, sob a condição de que estas sejam escolhidas adequadamente.

Até o momento, apenas a ideia por trás do emprego das funções de base foi apresentada, enquanto as formas das funções $\chi_{u}$ continuam indefinidas. Neste trabalho, funções de base do tipo gaussianas são geradas. Para melhor contextualização, nos próximos tópicos serão apresentados três tipos de funções de base: hidrogenóides, de Slater e gaussianas.

\subsubsection{Funções Hidrogenóides}

Por serem soluções exatas da equação de Schrödinger para átomos monoeletrônicos, as funções do tipo hidrogenóides foram implementadas nos primeiros anos de desenvolvimento dos programas destinados a resolver as equações de Hartree-Fock [32]. As funções hidrogenóides, em coordenadas esféricas, têm a forma dada por:

$$
\chi_{n l m}=Y_{l m}(\theta, \Phi) R_{n l}(r)
$$

onde $n, l$ e $m$ são respectivamente os números quânticos principal, azimutal e magnético, $Y_{l m}(\theta, \Phi)$ contém a dependência angular e $R_{n l}(r)$ a dependência radial da função de onda $\chi_{n l m}$.

A forma explícita da dependência radial é:

$$
R_{n l}(r)=N(n, l)\left(\frac{2 Z r}{n}\right)^{l} \exp \left(\frac{-Z r}{n}\right) L_{n-l-1}^{2 l+1}\left(\frac{2 Z r}{n}\right)
$$


onde $N(n, l)$ é uma constante de normalização e $L_{n-l-1}^{2 l+1}\left(\frac{2 Z r}{n}\right)$ a representação genérica do polinômio associado de Laguerre de variável $\frac{2 Z r}{n}$.

A função de dependência angular $Y_{l m}(\theta, \Phi)$, também conhecida como harmônico esférico, têm a forma:

$$
Y_{l m}(\theta, \Phi)=N_{l m} \exp (\operatorname{im} \Phi) P_{l}^{m}(\cos \theta)
$$

sendo $N_{l m}$ um fator de normalização e as funções $P_{l}^{m}(\cos \theta)$ conhecidas como os polinômios associados de Legendre.

A ideia do uso de funções hidrogenóides em cálculos de estrutura eletrônica não foi muito longe, pois as integrais de 3 e 4 centros encontradas eram difíceis de serem calculadas devido à complexidade do polinômio associado de Laguerre, tornando-se bem mais complicado a medida que $n$ cresce [33].

\subsubsection{Funções de Slater}

Em 1930, John Clark Slater [34] apresentou uma forma analítica mais simples para a parte radial das funções hidrogenóides:

$$
R_{n}(r)=N(n, \zeta) r^{n^{*}-1} \exp (-\zeta r)
$$

em que $N(n, \zeta)$ é um fator de normalização, $n$ *e o número quântico principal efetivo e $\zeta$ é um parâmetro conhecido como expoente orbital. O expoente orbital é dado por:

$$
\zeta=\frac{Z-w}{n^{*}}
$$

sendo $\mathrm{Z}$ a carga nuclear e $w$ a constante de blindagem. A diferença entre essas duas constantes fornece a carga nuclear efetiva sentida por um determinado elétron. Os parâmetros $w$ e $n^{*}$ foram avaliados por Slater [34] a partir de regras empíricas conhecidas como regras de Slater. Os expoentes $\zeta$ são números positivos e determinam o comportamento radial da função. Um grande expoente remete a uma distribuição radial estreita e um pequeno expoente remete a uma distribuição radial mais difusa.

As funções de Slater, em inglês, Slater Type Function (STF), foram um dos primeiros casos de funções de base bem sucedidas em cálculos atômicos. Parte deste sucesso se deve a simplificação na determinação das integrais de energia, e a descrição correta da distribuição eletrônica em regiões de longo e curto alcance. 


\subsubsection{Funções Gaussianas}

Apesar de simplificar a resolução das integrais em cálculos atômicos, no domínio molecular, o uso das funções de Slater apresenta grandes dificuldades computacionais associadas ao cálculo de integrais multicêntricas (envolvendo interações eletrônicas). No início dos anos 50, Boys [35] sugeriu a utilização de funções gaussianas (GTF - do inglês, Gaussian Type Functions) como alternativa prática em cálculos moleculares. Assim como as funções hidrogenóides e de Slater, as funções gaussianas respeitam a equação (1.2), diferindo apenas na maneira com que a dependência radial é representada matematicamente:

$$
R_{n}(r)=N(n, \alpha) r^{n-1} \exp \left(-\alpha r^{2}\right)
$$

sendo $N(n, \alpha)$ um fator de normalização, $n$ o número quântico principal e $\alpha$ o expoente gaussiano. Assim como nas funções de Slater, os expoentes $\alpha$ influenciam na distribuição radial das funções gaussianas, que por sua vez definem a forma dos orbitais.

A principal diferença estética entre as GTF's' em relação às STF's é a dependência quadrática da variável $r$ no termo exponencial. Além da conclusão óbvia de que as funções gaussianas tendem a decair muito mais rápido que as funções de Slater, a diferença no termo exponencial confere às gaussianas propriedades específicas [32]. O produto de duas ou mais funções gaussianas será também uma função gaussiana [36]. Por uma questão de simplicidade, trataremos de gaussianas em coordenadas cartesianas. De modo ilustrativo, tomemos duas funções gaussianas quaisquer $\mathrm{G}\left(\alpha_{1}, \mathrm{r}_{\mathrm{A}}\right)$ e $\mathrm{G}\left(\alpha_{2}, \mathrm{r}_{\mathrm{B}}\right)$, centradas nas coordenadas $A=\left(A_{x}, A_{y}, A_{z}\right)$ e $B=\left(B_{x}, B_{y}, B_{z}\right)$, respectivamente. $O$ produto entre essas gaussianas será uma terceira função gaussiana $G\left(\alpha_{3}, r_{C}\right)$ centrada no ponto $C=\left(C_{x}, C_{y}, C_{z}\right)$ :

$$
G\left(\alpha_{1}, r_{A}\right) \cdot G\left(\alpha_{2}, r_{B}\right)=K \cdot G\left(\alpha_{3}, r_{C}\right)
$$

sendo K, um fator pré-exponencial, dado por:

$$
K=\exp \left(-\frac{\alpha_{1} \alpha_{2}}{\alpha_{1}+\alpha_{2}} \overline{A B}^{2}\right)
$$

e o expoente da nova gaussiana

$$
\alpha_{3}=\alpha_{1}+\alpha_{2}
$$


$\mathrm{O}$ valor $\overline{A B}$ é simplesmente a separação relativa entre os centros das gaussianas 1 e 2 . As coordenadas do ponto $\mathrm{C}$ são encontradas por expressões semelhantes às do cálculo de um centro de massa para um sistema de dois centros:

$$
\begin{aligned}
& C_{x}=\frac{\alpha_{1} A_{x}+\alpha_{2} B_{x}}{\alpha_{1}+\alpha_{2}} \\
& C_{y}=\frac{\alpha_{1} A_{y}+\alpha_{2} B_{y}}{\alpha_{1}+\alpha_{2}} \\
& C_{z}=\frac{\alpha_{1} A_{z}+\alpha_{2} B_{z}}{\alpha_{1}+\alpha_{2}}
\end{aligned}
$$

A regra do produto entre gaussianas simplifica significativamente a resolução de integrais. Por exemplo, integrais de dois centros são reduzidas a integrais de um centro, enquanto integrais de quatro centros se reduzem a integrais de dois centros, permitindo sua resolução analítica. E este é o principal motivo pelo qual as funções gaussianas são tão empregadas em cálculos de estrutura eletrônica. Por infortúnio, funções do tipo gaussiana não reproduzem o comportamento de orbitais tão bem quanto as funções de Slater e, de modo geral, são necessários um número maior de funções gaussianas para atingir o mesmo grau de precisão nos cálculos que se alcançaria utilizando um menor número de funções de Slater. No fim, a maior velocidade e simplicidade na resolução das integrais de interação eletrônica compensa o elevado número de integrais derivadas das funções gaussianas.

\subsection{Qualidade dos Conjuntos de Base}

No decorrer do texto foi mencionado que várias funções são necessárias para descrever um orbital atômico/molecular com certo nível de precisão, em outras palavras, o "tamanho" da base está intimamente relacionado à qualidade dos resultados teóricos. A quantidade de funções necessárias ao cálculo vai depender principalmente da acurácia desejada e da extensão (em átomos) do sistema a ser estudado. Tantas mais funções de base são exigidas quanto maior a exatidão desejada e complexidade do modelo. Na literatura, é comum designar uma qualidade ao conjunto de base conforme o número de funções de base por simetria que o compõe. Os próximos tópicos tratarão de algumas definições acerca da qualidade dos conjuntos de base. 


\subsubsection{O Conjunto de Base Mínima}

Conjuntos de base mínima, também conhecidos como single-zeta, são conjuntos que possuem apenas uma função de base para cada orbital atômico ocupado com números quânticos $n$ e $l$ distintos [37]. A título de exemplo, a base mínima para o Hidrogênio seria uma função para descrever o orbital 1s, enquanto que para o cloro seriam cinco tipos de funções, referentes aos orbitais $1 \mathrm{~s}, 2 \mathrm{~s}, 2 \mathrm{p}, 3 \mathrm{~s}$ e $3 \mathrm{p}$. As bases mínimas são os conjuntos mais simples que podem ser usados em cálculos ab initio.

\subsubsection{Base Double-Zeta e Base Estendida}

O uso de conjuntos de base maiores é essencial em situações onde estimativas precisas da energia e de outras propriedades do sistema são requeridas. Nestes casos, os conjuntos de bases levam mais de uma função para descrever cada orbital distinto em $n$ e $l$ do átomo. Nos conjuntos de qualidade double-zeta, por exemplo, cada orbital atômico é representado por uma combinação linear de duas funções de base com diferentes expoentes. Conjuntos de base maiores que double-zeta são conhecidos genericamente como conjuntos de base estendida, embora haja outras denominações para bases de maiores. Por exemplo, em conjuntos triplezeta são utilizadas combinações lineares de três funções de base para desenhar cada orbital atômico de nível e momento angular distinto. O mesmo raciocínio da nomenclatura pode ser aplicado às bases de qualidade $N$-zeta (onde $N=4,5,6, \ldots$ ).

\subsubsection{Conjuntos do tipo Split-Valence}

As bases do tipo split-valence são conjuntos em que apenas os orbitais de valência são descritos por mais de uma função de base, enquanto orbitais do caroço são descritos por apenas uma função. Os conjuntos do tipo Split-valence são amplamente utilizados, sendo o modelo adotado por bases bastante populares como: 4-31G, 6-31G, cc-pVNZ (N=D, T, Q, $5 \ldots)$, etc.

A estruturação deste tipo de base baseia-se numa aproximação, racional, de que os orbitais atômicos mais internos sofrem pouca mudança durante o processo de formação das ligações químicas que constituem a molécula. Desta forma, espera-se que os orbitais do caroço contribuam menos para a maioria das propriedades químicas, variando pouco de molécula para molécula. Consequentemente, mais esforços computacionais podem ser concentrados na melhor descrição dos orbitais de valência, essenciais para a obtenção de 
propriedades moleculares. Para fins práticos, a não duplicação de funções de base para orbitais do caroço tem algum efeito na energia total, mas reflete pouco nos momentos de dipolo, potenciais de ionização de valência, densidade de carga, energia de dissociação e em outras grandezas de relevância química [33].

\subsection{Determinação dos Expoentes: O Método Variacional}

Tão importante quanto determinar a qualidade ou o tipo da função de base, é determinar os expoentes de cada função, pois estes são responsáveis por definir as características das bases. Um dos critérios mais utilizados na obtenção dos expoentes do conjunto de base é o Método Variacional [38]. Segundo o teorema do valor médio, uma função de onda aproximada $\Psi_{\text {aprox }}$, representando um sistema arbitrário qualquer, fornece um valor de energia dado pela expressão:

$$
\left\langle E_{\text {aprox }}\right\rangle=\frac{\left\langle\Psi_{\text {aprox }}|H| \Psi_{\text {aprox }}\right\rangle}{\left\langle\Psi_{\text {aprox }} \mid \Psi_{\text {aprox }}\right\rangle}
$$

De acordo com o teorema variacional, a energia $E_{\text {aprox }}$ será sempre maior, ou na melhor das hipóteses igual, a energia exata $E_{\text {ext }}$. Infelizmente soluções exatas da equação de Schrödinger para sistemas com mais de um elétron são desconhecidas, e na prática também não sabemos qual valor de $E_{\text {ext }}$. Todavia, imaginemos a existência de um conjunto de soluções tentativas $\Psi_{1}, \Psi_{2}, \Psi_{3}, \ldots$, que geram energias $E_{1}, E_{2}, E_{3}, \ldots$, respectivamente. Segundo o teorema variacional, a melhor função tentativa será aquela que fornecer o menor valor de energia, pois estará mais próxima do valor exato $E_{\text {ext }}$, que funciona de maneira análoga a um limite assintótico. Por exemplo, para o caso de $E_{3}<E_{1}<E_{2}<\ldots$, então $\Psi_{3}$ seria a função que representa o sistema de maneira mais adequada e, sem dúvida, $E_{3} \geq E_{\text {ext }}$. Contudo, muito cuidado deve ser tomado na interpretação das funções tentativas, pois a medida que a função tentativa é aprimorada, a energia tende a aproximar-se do valor real mais rapidamente do que a função de onda tende a se aproximar da função exata [39].

A adoção do método variacional para construção de bases atômicas permite decidir qual o melhor grupamento de funções, pois o conjunto ótimo de expoentes será aquele que propicie a menor energia eletrônica para o sistema em questão. Deste modo, os expoentes atuam nas funções de base como parâmetros variacionais, que são modificados no intuito de encontrar o ponto mínimo da energia eletrônica. Os valores ótimos dos expoentes variam conforme o 
Hamiltoniano do problema, número de funções de base e a metodologia de cálculo eletrônico ao qual esses parâmetros se ajustarão.

\subsection{Contração do Conjunto de Base}

No decorrer do texto, foi mencionado que, em metodologias de cálculo eletrônico, os orbitais atômicos e moleculares são descritos como combinações lineares de funções de base. Os coeficientes das combinações funcionam como parâmetros variacionais, e sua determinação compõe uma etapa dispendiosa em tempo computacional. Estima-se que o custo computacional de cálculos atômicos e moleculares cresça proporcional ao número de funções de base numa escala de $\mathrm{N}^{4}$ para cálculos HF e $\mathrm{N}^{5}$ para teoria de Møller-Plesset em nível MP2 [40]. Por esse motivo, a contração das funções de base tornou-se um procedimento essencial no desenvolvimento de conjuntos de base, principalmente quando se utilizam funções gaussianas.

A ideia do processo de contração é agrupar algumas das funções de base do conjunto, de acordo com sua simetria $(s, p, d \ldots)$, em uma combinação linear onde os coeficientes possuam valores já conhecidos. Para distinguir os tipos de funções do conjunto, costuma-se chamar as funções não contraídas de funções primitivas. Os coeficientes das funções contraídas podem ser escolhidos de maneira que se aproximem a funções de Slater, orbitais atômicos HF, ou qualquer outro tipo de função desejada.

Por uma questão didática, vamos por imaginação assumir que um átomo $\mathrm{X}$ possui um orbital espacial $\Phi_{1}$ representado por um conjunto de base composto de quatro funções exponenciais primitivas e hipotéticas:

$$
\Phi_{1}(r)=C_{1} e^{-\alpha_{1} r}+C_{2} e^{-\alpha_{2} r}+C_{3} e^{-\alpha_{3} r}+C_{4} e^{-\alpha_{4} r}
$$

A princípio, existem oito parâmetros variacionais, quatro coeficientes e quatro expoentes. Digamos que essa base foi otimizada em ambiente atômico, obtendo-se os valores ótimos para os expoentes e coeficientes, a base está pronta. Para a aplicação desta base em um cálculo molecular envolvendo $\mathrm{X}_{2}$, os expoentes permanecem inalterados, contudo, os coeficientes podem variar para descrever melhor o comportamento do novo orbital. Convencionalmente, outros procedimentos numéricos devem ser feitos para encontrar, mais uma vez, os valores ótimos dos coeficientes para esse novo sistema. 
A fim de diminuir o custo computacional da obtenção destes coeficientes, em nosso caso hipotético, agrupamos as duas primeiras funções do conjunto em uma só função, preservando seus coeficientes, enquanto os restantes permanecem livres:

$$
\Phi_{2}(r)=K_{1}\left(C_{1} e^{-\alpha_{1} r}+C_{2} e^{-\alpha_{2} r}\right)+K_{2} e^{-\alpha_{3} r}+K_{3} e^{-\alpha_{4} r}
$$

Neste caso, diz-se que nossa função contraída foi formada pela combinação de duas funções primitivas. Após a contração, nosso conjunto de funções agora é formado por três funções, uma contraída e duas primitivas. Como $C_{1}$ e $C_{2}$ foram otimizados em ambiente atômico, os parâmetros variacionais foram reduzidos também de 4 para $3, K_{1}, K_{2}$ e $K_{3}$. Como consequências desta mudança espera-se: 1) um menor tempo computacional para a convergência do cálculo atômico/molecular e 2) uma determinada perda na qualidade dos resultados. A segunda consequência é bastante lógica, pois quanto menor o número de parâmetros variacionais, menor será o grau de flexibilidade da base para se adequar a função de onda do sistema desejado.

O exemplo de contração citado no parágrafo anterior serve também para introduzir dois aspectos fundamentais no que se refere a construção de bases contraídas [32]:

- O número de funções no conjunto de base contraída deve ser significativamente menor do que o número de funções primitivas presentes na base descontraída.

- O conjunto de funções de base contraído deve fornecer valores de propriedades muito próximos dos valores obtidos com o conjunto de base não contraído.

Desta forma, é evidente que durante um processo de contração, deve-se buscar um balanço entre o ganho em termos de economia de custo computacional e perda na qualidade dos resultados.

No contexto de procedimentos para contração de bases, existem duas metodologias principais: o Método da Contração Segmentada e o Método da Contração Geral. O primeiro foi sugerido por T. H. Dunning [41], onde ele apresenta regras de contração que possuem um embasamento físico. De maneira concisa, Dunning afirma que as funções de base que representem regiões mais afastadas do núcleo, ou seja, orbitais mais difusos, devem permanecer não contraídas. Segundo ele, estas funções descrevem a região em que os orbitais atômicos são mais influenciados pela presença de múltiplos núcleos, portanto mais importantes durante a formação de moléculas. Outrossim, se uma mesma função primitiva 
contribuir significativamente para dois orbitais atômicos, esta função deve fazer parte das funções contraídas referentes a ambos os orbitais, pois representam regiões do espaço que possuem um peso importante na descrição das propriedades do sistema.

Apesar de conceitualmente interessante, o esquema de Dunning apresenta a dificuldade operacional de selecionar os coeficientes de contração quando muitas combinações são possíveis. Adicionalmente, Raffenetti [42] aponta outras desvantagens da contração segmentada, como a necessidade de ter muitas funções primitivas no conjunto para evitar a deterioração da energia à medida que os átomos vão ficando mais pesados. Em alternância, no método da Contração Geral todas as primitivas originais podem contribuir para cada função contraída. Na prática, isto significa utilizar os orbitais atômicos Hartree-Fock (construídos com as funções primitivas) como funções de base para realização de cálculos moleculares. $\mathrm{O}$ método da contração geral de Raffenetti foi adotado para a construção das bases do presente trabalho.

\subsection{Funções de Base Adicionais}

Via de regra, conjuntos de base são otimizadas em ambiente atômico em nível HartreeFock e, por conta disso, suas funções componentes possuem a mesma simetria dos orbitais

atômicos ocupados. Isto é, para o átomo de Flúor no estado fundamental $-{ }^{2} P\left(1 \mathrm{~s}^{2}, 2 \mathrm{~s}^{2}, 2 \mathrm{p}^{5}\right)$, o conjunto de base, a princípio, será composto de funções de base com simetria s e p apenas. No entanto, essas funções de base não levam em consideração as distorções da nuvem eletrônica, que exercem efeitos sobre a descrição de diversas propriedades atômicas e moleculares. Sob estas circunstâncias, é preciso que os conjuntos de base sejam complementados com outros tipos de função de base, a saber: funções de polarização e funções difusas.

\subsubsection{Funções de Polarização}

Nos conjuntos de base, as funções de polarização são funções de momento angular $l$ maior do que os encontrados nas funções do conjunto original. Voltando ao caso do flúor, a inclusão de funções de polarização corresponderia a adição de funções com simetria $d, f, g, h$, etc. O principal papel das funções de polarização é auxiliar no desenho de orbitais não esféricos e reproduzir o efeito de deformação causado pela presença de múltiplos núcleos. Seu uso é essencial para a reprodução adequada de estados excitados, ligações químicas, energias de dissociação, momentos dipolares, afinidade eletrônica, dentre outros. Os expoentes de polarização podem ser obtidos pelo ajuste variacional em ambiente molecular, ou atômico 
utilizando métodos que incluam efeitos de correlação eletrônica. Como de costume, o grau de melhora nos resultados dos cálculos vai depender da quantidade de funções de polarização adicionadas à base, embora a inclusão dessas funções aumente significativamente o tamanho da base.

\subsubsection{Funções Difusas}

Nos sistemas aniônicos, a nuvem eletrônica apresenta a tendência de expandir no espaço a fim de se estabilizar devido à presença do elétron extra na camada de valência. Conjuntos de bases ordinários, a princípio, não apresentam a competência de descrever adequadamente o comportamento de ânions e deste modo devem ser aumentados na região de valência pela inclusão de funções de base difusas para cada tipo de simetria presente. As funções difusas possuem expoentes menores em relação aos das funções presentes no conjunto original, o que significa que o elétron pode ser mantido ligado a distancias maiores do núcleo. Em geral, os expoentes das funções difusas são ajustados variacionalmente em ânions monoatômicos, enquanto o conjunto de base original é conservado. Além da sua importância na descrição de ânions, as funções difusas também são necessárias na computação acurada de propriedades como polarizabilidade, afinidade eletrônica, estados de Rydberg, energias de ligação por dispersão, etc.

\subsection{Os conjuntos de base aug-cc-pVQZ e aug-cc-pV5Z}

Os conjuntos de base aug-cc-pVQZ e aug-cc-pV5Z [43] e seus resultados serão utilizados como parâmetro comparativo para avaliar a eficiência das nossas bases. Tais conjuntos são conhecidos pela robustez de tamanho, e por fornecerem resultados acurados. Essas bases são derivadas dos conjuntos de base do Dunning, os "correlation-consistent" ccpVQZ, -pV5Z [44], onde os conjuntos neutros foram aumentadas (daí a abreviação aug, augmented) com funções adicionais, otimizadas para os ânions atômicos. Em síntese, uma função de base primitiva $s$ e outra $p$ foram adicionadas aos conjuntos $s$ e $p$ das bases cc-pVQZ e cc-pV5Z do átomo neutro, sendo os expoentes otimizados para a energia HF do ânion. Também foi acrescentada uma função de polarização adicional para cada simetria presente no conjunto, onde seus expoentes foram otimizados em ambiente CISD para o ânion em questão. Os conjuntos aug-cc-pVQZ e aug-cc-pV5Z possuem estrutura $(13 s 7 p 4 d 3 f 2 g) /[6 s 5 p 4 d 3 f 2 g]$ e $(15 s 9 p 5 d 4 f 3 g 2 h) /[7 s 6 p 5 d 4 f 3 g 2 h]$, respectivamente. 


\section{Objetivo}

Esta dissertação tem por objetivo desenvolver funções de base otimizadas em ambiente aniônico para os elementos B, C, O e F, com vista ao cálculo de afinidade eletrônica.

\subsection{Objetivos Específicos}

- Gerar conjuntos de base pelo método da coordenada geradora Hartree-Fock, em simultâneo com a técnica de Discretização Integral Polinomial (DIP).

- Contrair os conjuntos de base pelo método da contração geral.

- Adicionar funções de polarização aos conjuntos contraídos.

- Avaliar a eficiência das bases na predição teórica da afinidade eletrônica para os átomos de $\mathrm{B}, \mathrm{C}, \mathrm{O}$ e $\mathrm{F}$, bem como para as moléculas $\mathrm{BO}, \mathrm{C}_{2}, \mathrm{O}_{2}$ e FO. 


\section{Metodologia}

Nesta seção serão apresentados tópicos que descrevem de maneira mais detalhada os procedimentos matemáticos e as ideias por trás das técnicas utilizadas durante a execução deste trabalho. Entretanto, para que o leitor venha a ter uma visão mais prática e geral da metodologia utilizada, segue abaixo, em forma resumida, todas as etapas ao qual a pesquisa foi submetida:

1) Desenvolvimento dos conjuntos de base

Para a geração dos conjuntos de base foi utilizado o programa ATOM-SCF, onde foi implementado por Morgon e Haiduke [45] o método da coordenada geradora em conjunto com o tratamento das integrais pela Discretização Integral Polinomial. Para todos os átomos e seus ânions, foram gerados conjuntos de tamanho $18 s 13 p$.

2) Contração dos conjuntos de base

A contração das bases foi feita pelo método da contração geral do Raffenetti [42], utilizando as considerações feitas por Hashimoto et al. [46]. As bases foram contraídas para conjuntos de qualidade sêxtuplo-zeta de valência, sendo o conjunto de $(18 s 13 p)$ primitivas contraído para $[7 s 6 p]$.

3) Polarização dos conjuntos de base

A polarização dos conjuntos de base foi realizada para cada conjunto, no total foram adicionados para cada átomo quatro funções $d$, três funções $f$ e duas funções $g$. Posteriormente, a fim de avaliar a completeza da base, foi avaliado o efeito da adição de uma função do tipo $h$ aos conjuntos de base. Deste modo, para cada átomo neutro e negativamente carregado, foram gerados conjuntos $[7 s 6 p 4 d 3 f 2 g]$ e $[7 s 6 p 4 d 3 f 2 g 1 h]$. Os expoentes das funções de polarização foram otimizados em ambiente CISD através do método SIMPLEX [47].

4) Avaliação dos conjuntos de base: Cálculo das Afinidades Eletrônicas

A afinidade eletrônica foi calculada pela subtração entre a energia eletrônica das espécies neutra e carregada negativamente. Para determinação das energias eletrônicas foi utilizado o programa GAUSSIAN 09 [48]. Como as moléculas aqui estudadas são todas lineares, não foi necessário o uso de programas para desenho molecular como o GaussView. 
Todos os cálculos atômicos foram realizados em nível QCISD(T)=FULL, considerando excitações simples, duplas, e triplas perturbativas possíveis do espaço gerado pelos conjuntos de base. Devido a limitações de hardware os cálculos moleculares foram processados em nível QCISD, onde apenas os elétrons de valência são incluídos no cálculo da correlação.

Todas as atividades da pesquisa (desenvolvimento das bases e cálculos teóricos) foram executados em duas máquinas: um desktop institucional do grupo de Química Quântica da USP, e um desktop de uso pessoal i7-3770, 16 GB RAM, placa mãe ASUS chipset Z77, GPU NVIDIA GTX 760.

\subsection{Geração dos Conjuntos de Base}

Como já foi mencionado, os conjuntos de base foram gerados pelo Método da Coordenada Geradora Hartree-Fock (MCG-HF). Seria deselegante que o texto apresentasse o MCG-HF sem antes ter introduzido ao leitor a ideia e a matemática ao qual se embasa o método Hartree-Fock. Desta maneira, o próximo tópico tratará dos aspectos e equações mais gerais do método Hartree-Fock.

\subsubsection{O Método Hartree-Fock}

Devido às dificuldades para se resolver exatamente a equação de Schrödinger em sistemas multieletrônicos, métodos que tratam os problemas de maneira aproximada foram propostos. O método Hartree-Fock [49] é um destes métodos, e é utilizado na determinação das propriedades de sistemas quânticos de muitos corpos em estado estacionário (energia invariante com o tempo), além de servir como ponto de partida para métodos mais refinados.

O método Hartree-Fock é baseado em cinco aproximações principais. A primeira delas é supor que a função de onda de um sistema de n partículas, $\Psi\left(r_{1}, r_{2}, \ldots, r_{n}\right)$, pode ser descrita por um único determinante de Slater, um produto anti-simetrizado de funções de um elétron:

$$
\Psi\left(r_{1}, r_{2}, \ldots, r_{n}\right)=\left|\Phi_{1}\left(r_{1}\right) \bar{\Phi}_{1}\left(r_{2}\right) \Phi_{2}\left(r_{3}\right) \bar{\Phi}_{2}\left(r_{4}\right) \ldots \bar{\Phi}_{\frac{n}{2}}\left(r_{n}\right)\right|
$$

onde $r_{i}$ é o conjunto de coordenadas espaciais e de spin do elétron $i$. A equação (3.1) é um caso especial do método, conhecido como Hartree-Fock Restrito, ou RHF, pois em sistemas de camada fechada, os pares de elétrons podem ser restringidos a ocuparem o mesmo orbital espacial. De modo que as funções monoeletrônicas são representadas como: 


$$
\Phi_{j}(i)=\Phi_{j}(i) \alpha(i) \quad \text { e } \quad \bar{\Phi}_{j}(i)=\Phi_{j}(i) \beta(i)
$$

sendo $\alpha(i)$ e $\beta(i)$ funções de spin. As funções $\Phi_{j}(i)$ são funções que representam matematicamente orbitais atômicos ou moleculares.

A partir deste ponto, são assumidas outras duas aproximações, agora na construção do hamiltoniano. Os efeitos relativísticos e de spin-órbita são completamente negligenciados, deste modo, o operador de energia cinética é assumido ser completamente não relativístico. Além disso, também é aplicada a aproximação do campo médio para tratar das interações eletrônicas no hamiltoniano HF. De maneira sucinta, na teoria do campo médio, o efeito de todas as outras partículas numa dada partícula individual é aproximado como apenas um efeito de campo médio, reduzindo um problema de muitos corpos a vários problemas de único corpo, mais simples de se lidar. Deste modo, o hamiltoniano "completo" HF para um sistema de $n$ elétrons e $m$ núcleos, em unidade atômica é:

$$
\widehat{H}=-\sum_{i}^{n} \frac{1}{2} \nabla_{i}^{2}-\sum_{a}^{m} \frac{1}{2 M_{a}} \nabla_{a}^{2}-\sum_{i}^{n} \sum_{a}^{m} \frac{Z_{a}}{r_{i a}}+\sum_{i}^{n} \sum_{j>i}^{n} \frac{1}{r_{i j}}+\sum_{a}^{m} \sum_{b>a}^{m} \frac{Z_{a} Z_{b}}{R_{a b}}
$$

onde $M_{a}$ é a razão entre a massa do núcleo $a$ e a massa de um elétron, e $Z_{a}$ é o número atômico do núcleo $a$. Os termos $\nabla_{i}^{2}$ e $\nabla_{a}^{2}$ sãos os operadores Laplacianos para os $i$ elétrons e $a$ núcleos, e representam os termos de energia cinética. $O$ terceiro termo representa a atração coulombiana entre elétrons e núcleos, enquanto o quarto e quinto termos de (3.3) correspondem à repulsão elétron-elétron e núcleo-núcleo, respectivamente.

A quarta aproximação, é baseada no fato de que, pelos núcleos serem muito mais pesados que os elétrons, os elétrons movem-se de maneira muito mais rápida que os núcleos. Desta forma, é admissível considerar a situação em que os núcleos estão fixos enquanto os elétrons executam seus movimentos. O resultado da chamada aproximação de BornOppenheimer [39] é a redução do hamiltoniano molecular no hamiltoniano do problema eletrônico:

$$
\widehat{H}_{e l}=-\sum_{i}^{n} \frac{1}{2} \nabla_{i}^{2}-\sum_{i}^{n} \sum_{a}^{m} \frac{Z_{a}}{r_{i a}}+\sum_{i}^{n} \sum_{j>i}^{n} \frac{1}{r_{i j}}
$$


No intuito de encontrar a energia eletrônica de um sistema qualquer via método HF, aplica-se a forma da função de onda da equação (3.1) na expressão da energia segundo o teorema do valor médio:

$$
E=\left\langle\Psi\left(r_{1}, r_{2}, \ldots, r_{n}\right)|H| \Psi\left(r_{1}, r_{2}, \ldots, r_{n}\right)\right\rangle
$$

Como as funções de onda HF são normalizadas, o denominador da expressão (3.5) é um. Empregando propriedades algébricas distributivas, a expressão acima pode ser detalhada em termos de funções monoeletrônicas:

$$
E=2 \sum_{i}^{n / 2} h_{i i}+\sum_{i}^{n / 2} \sum_{j}^{n / 2}\left(2 J_{i j}-K_{i j}\right)
$$

sendo

$$
h_{i i}=\left\langle\Phi_{i}\left|h\left(r_{1}\right)\right| \Phi_{i}\right\rangle
$$

com o operador $h\left(r_{1}\right)$ dado por

$$
h\left(r_{1}\right)=-\frac{1}{2} \nabla_{1}^{2}-\sum_{a}^{m} \frac{Z_{a}}{r_{1 a}}
$$

onde $Z_{a}$ é a carga do núcleo $a, r_{1 a}$ é a distância do elétron 1 ao núcleo $a$, e o $-\frac{1}{2} \nabla_{1}^{2}$ é o laplaciano para a energia cinética do elétron 1. Os outros dois termos da equação (3.6) são:

$$
J_{i j}=\left\langle\Phi_{i}\left(r_{1}\right) \Phi_{j}\left(r_{2}\right)\left|\frac{1}{r_{12}}\right| \Phi_{i}\left(r_{1}\right) \Phi_{j}\left(r_{2}\right)\right\rangle
$$

$\mathrm{e}$

$$
K_{i j}=\left\langle\Phi_{i}\left(r_{1}\right) \Phi_{j}\left(r_{2}\right)\left|\frac{1}{r_{12}}\right| \Phi_{j}\left(r_{1}\right) \Phi_{i}\left(r_{2}\right)\right\rangle
$$

A integral $h_{i i}$ é também chamada de integral de um elétron, representando a soma da energia cinética de um elétron no orbital $\Phi_{i}$ e sua energia potencial de atração em relação aos núcleos. As integrais $J_{i j}$ e $K_{i j}$ são conhecidas como integrais de dois elétrons. A integral de Coulomb $J_{i j}$ pode ser interpretada classicamente como a interação entre duas distribuições de cargas, enquanto $K_{i j}$, a integral de troca, não possui equivalente clássico e se relaciona diretamente ao principio da anti-simetria, sendo muitas vezes chamada de repulsão de Pauli. 
Para encontrar a forma dos spin-orbitais, utiliza-se o teorema variacional de modo a buscar os spin-orbitais que minimizem o valor da energia. Isso é feito a partir do teorema do valor médio [37], onde se constrói o funcional da energia em termos de $\Psi$ :

$$
E[\Psi]=\frac{\left\langle\Psi\left(r_{1}, r_{2}, \ldots, r_{n}\right)|H| \Psi\left(r_{1}, r_{2}, \ldots, r_{n}\right)\right\rangle}{\left\langle\Psi\left(r_{1}, r_{2}, \ldots, r_{n}\right) \mid \Psi\left(r_{1}, r_{2}, \ldots, r_{n}\right)\right\rangle}
$$

Sabendo que a função de onda é dependente da forma de seus orbitais, eq. (3.1), pode-se variar a energia para cada orbital, de modo que a condição de mínimo é dada por $\delta E / \delta \Phi_{i}=$ 0. Como é pertinente que os spin-orbitais se mantenham ortogonais entre si durante a variação, aplica-se ao problema o método dos multiplicadores indeterminados de Lagrange, com a condição do vínculo de ortonormalidade:

$$
\left\langle\Phi_{i}\left(r_{1}\right) \mid \Phi_{j}\left(r_{1}\right)\right\rangle=\delta_{i j}=\left\{\begin{array}{l}
0 \text { se } i \neq j \\
1 \text { se } i=j
\end{array}\right.
$$

sendo $\delta_{i j}$ o delta de Kronecker. Como resultado, obtêm-se as equações monoeletrônicas de Hartree-Fock:

$$
F(i) \Phi_{j}(i)=\varepsilon_{j} \Phi_{j}(i), \quad i=r_{1}, \ldots, r_{n}
$$

em que $F(i)$ é o operador de Fock, definido por:

$$
F(i)=h(i)+\sum_{k}^{n / 2}\left[2 J_{k}(i)-K_{k}(i)\right]
$$

As entidades $J_{k}$ e $K_{k}$ são os operadores de Coulomb e de troca, respectivamente, tendo as formas:

$$
J_{k}(i) \Phi_{j}(i)=\left[\int \Phi_{k}^{*}(l) \frac{1}{r_{i l}} \Phi_{k}(l) d \tau_{l}\right] \Phi_{j}(i)
$$

$\mathrm{e}$

$$
K_{k}(i) \Phi_{j}(i)=\left[\int \Phi_{k}^{*}(l) \frac{1}{r_{i l}} \Phi_{j}(l) d \tau_{l}\right] \Phi_{j}(i)
$$


Na expressão (3.14), o termo $\sum_{k}^{\frac{n}{2}}\left[2 J_{k}(i)-K_{k}(i)\right]$ é conhecido como Potencial Hartree-Fock, e representa o potencial médio sentido pelo elétron $i$ em função da presença dos outros, assumido conforme a aproximação do campo médio.

As equações (3.13) não são lineares pois a forma dos spin-orbitais vai depender do operador de Fock, que por sua vez é também depende dos spin-orbitais (vide expressões 3.1416). Por este motivo, a resolução das equações (3.13) é feita por um processo interativo, conhecido como Campo Autoconsistente, em inglês, Self-Consistent-Field (SCF). De maneira simples, no procedimento SCF faz se um "chute" inicial nas formas dos spin-orbitais, em seguida constrói-se o potencial Hartree-Fock a partir dos spin-orbitais tentativa e desenvolvese o operador de Fock. Agora as equações são apenas uma série de problemas de autovalor. Ao resolver as equações variacionalmente, encontram-se novos conjuntos de spin-orbitais. Esses spin-orbitais podem ser aplicados para gerar novos potenciais e consequentemente novos operadores de Fock para construir outras equações que devem ser resolvidas. O procedimento é repetido até que não haja mais variação significativa na forma dos spinorbitais.

Ao final do processo SCF, são obtidos os valores $\varepsilon_{j}$, frequentemente chamados de energia orbital. As $\varepsilon_{j}$ podem ser interpretadas como a energia de um elétron no orbital $\Phi_{j}$, decorrente de sua energia cinética, a atração com os elétron-núcleo e sua energia de troca e repulsão. Com base na equação (3.13) é verdade que:

$$
\varepsilon_{j}=\left\langle\Phi_{j}(i)|F(i)| \Phi_{j}(i)\right\rangle
$$

e que substituindo (3.14) em (3.17):

$$
\varepsilon_{j}=\left\langle\Phi_{j}(i)|h(i)| \Phi_{j}(i)\right\rangle+\sum_{k}^{n / 2}\left(2 J_{j k}-K_{j k}\right)
$$

ou ainda

$$
\varepsilon_{j}=h_{j j}+\sum_{k}^{n / 2}\left(2 J_{j k}-K_{j k}\right)
$$


Com a expressão integral (3.19), pode-se buscar uma maneira de descrever a energia total E em função das energias orbitais $\varepsilon_{j}$. A princípio, poder-se-ia pensar que a energia HF é o somatório de todas as energias $\varepsilon_{j}$ de spin-orbitais ocupados pelos $n$ elétrons:

$$
2 \sum_{j}^{n / 2} \varepsilon_{j}=2 \sum_{j}^{n / 2}\left[h_{j j}+\sum_{k}^{n / 2}\left(2 J_{j k}-K_{j k}\right)\right]
$$

e subtraindo da expressão E para o RHF, (3.6), obtêm-se a relação:

$$
E-2 \sum_{j}^{n / 2} \varepsilon_{j}=-\sum_{j}^{n / 2} \sum_{k}^{n / 2}\left(2 J_{j k}-K_{j k}\right)
$$

reescrevendo

$$
E=\sum_{j}^{n / 2}\left[2 \varepsilon_{j}-\sum_{k}^{n / 2}\left(2 J_{j k}-K_{j k}\right)\right]
$$

A simples análise da expressão (3.21) indica que o somatório das energias orbitais é um valor maior que o da energia Hartree-Fock, de modo que o sistema descrito seria menos estável do que realmente é. A explicação é que a soma de todas as energias orbitais $\varepsilon_{j}$ estaria contando as repulsões elétron-elétron em dobro.

Para sistemas atômicos, o calculo HF pode ser resolvido numericamente. Contudo, muitas dificuldades surgem a medida que o número de elétrons aumenta, de modo a tornar-se impraticável em sistemas moleculares [37]. Em 1951, Roothaan [50] propôs a quinta e última principal aproximação do método HF, que seria a implementação das funções de base para descrever as funções monoeletrônicas.

Aplicando a ideia das funções de base, eq. (1.1), na expressão da energia HF (3.6) fornece:

$$
E=2 \sum_{i}^{n / 2} \sum_{u} \sum_{v} C_{u i}^{*} C_{v i} H_{u v}+\sum_{i}^{n / 2} \sum_{j}^{n / 2} \sum_{u} \sum_{v} \sum_{r} \sum_{w} C_{u i}^{*} C_{r j}^{*} C_{v i} C_{w j}[2\langle u r \mid v w\rangle-\langle u v \mid r w\rangle]
$$

em que 


$$
H_{u v}=\left\langle\chi_{u}\left(r_{1}\right)\left|h\left(r_{1}\right)\right| \chi_{v}\left(r_{1}\right)\right\rangle
$$

onde $h\left(r_{1}\right)$ tem a mesma forma que em (3.8), e os termos entre colchetes em (3.22) são:

$$
\langle u r \mid v w\rangle=\iint \chi_{u}^{*}\left(r_{1}\right) \chi_{r}^{*}\left(r_{2}\right)\left|\frac{1}{r_{12}}\right| \chi_{v}\left(r_{1}\right) \chi_{w}\left(r_{2}\right) d \tau_{1} d \tau_{2}
$$

e

$$
\langle u v \mid r w\rangle=\iint \chi_{u}^{*}\left(r_{1}\right) \chi_{v}^{*}\left(r_{2}\right)\left|\frac{1}{r_{12}}\right| \chi_{r}\left(r_{1}\right) \chi_{w}\left(r_{2}\right) d \tau_{1} d \tau_{2}
$$

Os coeficientes introduzidos pela expansão dos orbitais HF são parâmetros variacionais. Através da equação (3.22), os melhores valores para os coeficientes são encontrados variando-se a energia eletrônica com respeito aos mesmos. Ao empregar um procedimento análogo àquele que levou às equações HF, variando a energia para cada coeficiente de expansão, chega-se as equações Hartree-Fock-Roothan:

$$
\sum_{v} C_{v i}\left\{h_{u v}+\sum_{j}^{n / 2} \sum_{v} \sum_{w} C_{v j} C_{w j}[2\langle u r \mid v w\rangle-\langle u v \mid r w\rangle]\right\}=\sum_{j}^{n / 2} \sum_{v} \varepsilon_{i j} C_{v j} S_{u v}
$$

onde o termo entre chaves é o operador de Fock, $F_{u v}$, para as equações de Roothaan:

$$
F_{u v}=h_{u v}+\sum_{j}^{n / 2} \sum_{v} \sum_{w} C_{v j} C_{w j}[2\langle u r \mid v w\rangle-\langle u v \mid r w\rangle]
$$

e $S_{u v}$ são os elementos da integral de recobrimento:

$$
S_{u v}=\left\langle\chi_{u}(i) \mid \chi_{v}(i)\right\rangle
$$

A equação (3.26) pode ser reescrita como:

$$
\sum_{v} C_{v i} F_{u v}=\sum_{j}^{n / 2} \sum_{v} \varepsilon_{i j} C_{v j} S_{u v}, \quad u=1,2,3, \ldots, t
$$

Na equação (3.29) é realizada uma transformação unitária na matriz dos autovalores $\varepsilon$, que com algumas modificações nos termos, resulta na expressão:

$$
\sum_{v}\left(F_{u v}-\varepsilon_{i} S_{u v}\right) C_{v i}=0, \quad u=1,2,3, \ldots, t
$$


A equação (3.29) também pode ser escrito em notação matricial como:

$$
\mathrm{FC}=\mathrm{SCE}
$$

sendo F, C, S e E as matrizes de Fock, coeficientes, recobrimento e autovalores, respectivamente. De maneira análoga às equações HF, as equações (3.31) são resolvidas de forma iterativa, onde orbitais moleculares são aproximados como uma combinação linear de orbitais atômicos, que por sua vez, são aproximados como uma combinação linear de funções de base.

\subsubsection{O Método da Coordenada Geradora Hartree-Fock}

O MCG-HF é uma derivação originada da versão Griffin-Wheeler das equações de Hartree-Fock, proposta em 1986 por Mohallem, Dreizler e Trsic [51]. A raiz do MCG-HF, o Método da Coordenada Geradora (MCG), foi introduzido em 1953 por Hill e Wheeler [52] com o objetivo de associar o movimento coletivo com o das partículas individuais. Quatro anos depois, Griffin e Wheeler [53] apresentaram uma formulação variacional do método, seguida de sua aplicação direta por Griffin [54] no tratamento das excitações dilatacionais e de quadrupolo do núcleo de $\mathrm{O}^{16}$. Em 1970, Wong [55] fez a correspondência do MCG com a equação de Schrödinger em um espaço truncado, tornando o MCG um método de aplicação geral.

Na ideia de Hill e Wheeler [52], que depois foi simplificada por Griffin-Wheeler [53], a função de onda tentativa para um cálculo variacional é dada por:

$$
\left|\Psi\left(r_{1, \ldots, r_{n}}\right)\right\rangle=\int f(\alpha)\left|\Phi\left(r_{1}, \ldots, r_{n}, \alpha\right)\right\rangle d \alpha
$$

onde $r$ é o conjunto de coordenadas espaciais e de spin, $\alpha$ a coordenada geradora, e $\Phi\left(r_{1}, \ldots, r_{n}, \alpha\right)$ é a função geradora. A função peso $f(\alpha)$ é inicialmente desconhecida, e deve ser determinada de modo a minimizar a energia do sistema para cada estado, ou seja, serve como um parâmetro variacional. Dito isto, a energia pode ser descrita como um funcional de $f(\alpha)$ :

$$
E[f(\alpha)]=\frac{\left\langle\Psi\left(r_{1}, \ldots, r_{n}\right)|H| \Psi\left(r_{1}, \ldots, r_{n}\right)\right\rangle}{\left\langle\Psi\left(r_{1}, \ldots, r_{n}\right) \mid \Psi\left(r_{1}, \ldots, r_{n}\right)\right\rangle}
$$

onde $\widehat{H}$ é o hamiltoniano do sistema. Impondo a condição $\delta E / \delta f(\alpha)=0$, chega-se à equação de autovalores de Griffin-Wheeler (GW): 


$$
\int[H(\alpha, \beta)-E S(\alpha, \beta)] f(\beta) d(\beta)=0
$$

sendo

$$
H(\alpha, \beta)=\left\langle\Phi\left(r_{1}, \ldots, r_{n}, \alpha\right)|H| \Phi\left(r_{1}, \ldots, r_{n}, \beta\right)\right\rangle
$$

e

$$
S(\alpha, \beta)=\left\langle\Phi\left(r_{1}, \ldots, r_{n}, \alpha\right) \mid \Phi\left(r_{1}, \ldots, r_{n}, \beta\right)\right\rangle
$$

$H(\alpha, \beta)$ e $S(\alpha, \beta)$ são os núcleos de energia e recobrimento, respectivamente, e possuem propriedades hermitianas, sendo assim $H(\alpha, \beta)=H^{*}(\alpha, \beta)$ e $S(\alpha, \beta)=S^{*}(\alpha, \beta)$. A solução da equação GW fornece os autovalores das energias do sistema nos estados estacionários possuindo mesma simetria que $\Phi\left(r_{1}, \ldots, r_{n}, \alpha\right)$, além das funções peso $f(\alpha)$, necessárias para resolver a equação de superposição (3.32) que fornecerá as funções de estado $\Psi\left(r_{1, \ldots, r_{n}}\right)$.

No que diz respeito à escolha das coordenadas geradoras, adota-se a variável que possui o grau de liberdade mais importante para o sistema. Os potenciais cujo sistema é submetido, em geral, dependem de uma coordenada geradora. Por exemplo, a distância entre núcleos que colidem, para problemas de espalhamento, ou como veremos a frente, os expoentes orbitais num problema de cálculo eletrônico. Já as funções geradoras $\Phi\left(r_{1}, \ldots, r_{n}, \alpha\right)$ devem ser escolhidas dentro de um conjunto que possua as mesmas condições de contorno do problema a ser tratado e que sejam bem comportadas quando submetidas a estas condições. Soluções exatas de problemas similares menos complexos ou uma solução aproximada do próprio sistema podem ser tomadas como funções geradoras. Caso nenhum dos procedimentos anteriores seja possível, busca-se uma função qualquer de acordo com as características físicas do problema.

A resolução da equação Griffin-Wheeler não é trivial, são poucos exemplos de soluções analíticas, de modo que o uso de procedimentos numéricos é bastante comum. A aproximação de recobrimento gaussiano, utilizada por Griffin [54] na problemática do $\mathrm{O}^{16}$, e técnicas de discretização [56,57] são alternativas quando não há solução analítica para o problema.

Baseados no MCG, Mohallem, Dreizler e Trsic [51] apresentaram uma nova formulação das equações HF, conhecida como Método da Coordenada Geradora Hartee-Fock. As equações desse método, chamadas de equações Griffin-Wheeler-Hartree-Fock (equações 
GW-HF), são geradas quando é assumido que as funções monoeletrônicas do determinante de Slater podem ser expressas a partir da equação (3.32), assim:

$$
\left|\Psi_{i}\left(r_{1}\right)\right\rangle=\int f_{i}(\alpha)\left|\Phi_{i}\left(r_{1}, \alpha\right)\right\rangle d \alpha, \quad i=1,2, \ldots, n
$$

em que $\Phi_{i}\left(r_{1}, \alpha\right)$ são funções geradoras que assumem agora formas de funções de base, como as funções de Slater ou gaussianas. De maneira análoga ao MCG, $f_{i}(\alpha)$ são funções peso e $\alpha$ é a coordenada geradora. Agora, utilizando-se das novas funções $\Psi_{i}$, para sistemas de camada fechada com um número par de $n$ elétrons, elabora-se um determinante de Slater:

$$
\Psi\left(r_{1}, r_{2}, \ldots, r_{n}\right)=\left|\Psi_{1}\left(r_{1}\right) \bar{\Psi}_{1}\left(r_{2}\right) \Psi_{2}\left(r_{3}\right) \bar{\Psi}_{2}\left(r_{4}\right) \ldots \bar{\Psi}_{\frac{n}{2}}\left(r_{n}\right)\right|
$$

onde pares de elétrons ocupam o mesmo orbital espacial. Aplicando a condição $\delta E / \delta f(\alpha)=0$ de maneira semelhante à feita no MCG, obtêm-se as equações GW-HF:

$$
\int\left[F(\alpha, \beta)-\varepsilon_{i} S(\alpha, \beta)\right] f_{i}(\beta) d(\beta)=0, \quad i=1,2, \ldots, n
$$

O núcleo de energia ou de Fock, $F(\alpha, \beta)$, agora tem estrutura bem definida, pois o $H$ aplicado no MCG-HF é o hamiltoniano eletrônico HF, os $\varepsilon_{i}$ são autovalores de energia HF. Os núcleos de Fock e de recobrimento, $S(\alpha, \beta)$, são explicitados da seguinte forma:

$$
F(\alpha, \beta)=h(\alpha, \beta)+\sum_{j}^{n}\left[2 J_{j}(\alpha, \beta)-K_{j}(\alpha, \beta)\right]
$$

$\mathrm{e}$

$$
S(\alpha, \beta)=\left\langle\Phi_{i}\left(r_{1}, \alpha\right) \mid \Phi_{i}\left(r_{1}, \beta\right)\right\rangle
$$

O núcleo de Fock é composto pelos subnúcleos de um elétron e de dois elétrons, representados pelos termos $h(\alpha, \beta), J_{j}(\alpha, \beta)$ e $K_{j}(\alpha, \beta)$ :

$$
\begin{gathered}
h(\alpha, \beta)=\left\langle\Phi_{i}\left(r_{1}, \alpha\right)\left|h\left(r_{1}\right)\right| \Phi_{i}\left(r_{1}, \beta\right)\right\rangle \\
J_{j}(\alpha, \beta)=\iint f_{j}\left(\alpha^{\prime}\right) f_{j}\left(\beta^{\prime}\right) V\left(\alpha, \alpha^{\prime} ; \beta^{\prime}, \beta\right) d \alpha^{\prime} d \beta^{\prime} \\
K_{j}(\alpha, \beta)=\iint f_{j}\left(\alpha^{\prime}\right) f_{j}\left(\beta^{\prime}\right) V\left(\alpha, \alpha^{\prime} ; \beta, \beta^{\prime}\right) d \alpha^{\prime} d \beta^{\prime}
\end{gathered}
$$


O operador $h\left(r_{1}\right)$ carrega os termos de energia cinética e atração elétron-núcleo (3.8), assim como nas equações Hartree-Fock. Os super-núcleos $V\left(\alpha, \alpha^{\prime} ; \beta^{\prime}, \beta\right)$ e $V\left(\alpha, \alpha^{\prime} ; \beta, \beta^{\prime}\right)$ têm sentido análogo às integrais de Coulomb e de troca, respectivamente, e possuem a forma:

$$
V\left(\alpha, \alpha^{\prime} ; \beta^{\prime}, \beta\right)=\left\langle\Phi_{i}\left(r_{1}, \alpha\right) \Phi_{j}\left(r_{2}, \alpha^{\prime}\right)\left|r_{12}^{-1}\right| \Phi_{j}\left(r_{2}, \beta^{\prime}\right) \Phi_{i}\left(r_{1}, \beta\right)\right\rangle
$$

$\mathrm{e}$

$$
V\left(\alpha, \alpha^{\prime} ; \beta, \beta^{\prime}\right)=\left\langle\Phi_{i}\left(r_{1}, \alpha\right) \Phi_{j}\left(r_{2}, \alpha^{\prime}\right)\left|r_{12}^{-1}\right| \Phi_{i}\left(r_{2}, \beta\right) \Phi_{j}\left(r_{1}, \beta^{\prime}\right)\right\rangle
$$

As equações GW-HF são resolvidas para cada $i$, através de um procedimento interativo, partindo-se de uma função peso inicial e com um critério arbitrário numérico para a convergência. As soluções dessas equações fornecem as energias orbitais $\varepsilon_{i}$ e novas funções peso, que serão utilizadas no processo interativo para gerar outras funções peso, e assim sucessivamente até que a convergência seja alcançada [33]. Mohallem e Trsic [57] conseguiram obter solução analítica das equações GW-HF para o átomo de hidrogênio descrito por funções geradoras gaussianas. Todavia, o último caso é simples, e para sistemas mais complexos as integrais são de difícil evaluação, sendo necessário o uso de técnicas de discretização.

\subsubsection{A Discretização Integral e a Troca de Rótulos}

As técnicas de Discretização têm por objetivo transformar o sistema de equações diferenciais em um sistema de equações algébricas, mais fáceis de se resolver. Nos processos usuais de discretização, os $\alpha$ podem ser variados de maneira a minimizar a energia total do sistema. Tais processos de discretização são conhecidos como Discretização Variacional (DV), em que os pontos de discretização são avaliados variacionalmente [58, 59]. A aplicação da DV reduz o MCG ao método variacional de Rayleigh-Ritz, que por sua vez levam às equações de Roothaan [33]. O grande problema da técnica variacional é que os expoentes são otimizados em função de obter o melhor orbital 1s, energeticamente mais importante. Como resultado, os valores médios dos outros orbitais, que não o 1s, são prejudicados.

Em 1986, Mohallem [60] sugeriu que as equações GW-HF fossem resolvidas por um sistema conhecido como Discretização Integral (DI), como alternativa mais elegante à Discretização Variacional. Na discretização integral, são escolhidos $\mathrm{N}$ pontos igualmente espaçados que pretendem preencher o intervalo de integração onde diferentes funções peso $f_{i}(\alpha)$ são importantes. Dentre as vantagens de usar a DI em detrimento da DV, menciona-se: 
a) Economia no tempo computacional, pois evita-se a otimização de parâmetros não lineares;

b) A representação adequada de vários estados excitados em apenas uma única diagonalização;

c) A construção de melhores funções de onda ao expandir de forma mais efetiva o intervalo de integração, o que evita a incidência de situações semelhantes a supervalorização do orbital 1s na DV;

$\mathrm{Na}$ aplicação de STF's como função geradora, o procedimento DI é suficiente para cobrir uma quantidade significativa da região do intervalo de integração. O mesmo não pode ser dito sobre as $f(\alpha)$ para as GTF's, pois suas funções peso são muito espalhadas e tendem a decair de modo extremamente lento à medida que o valor dos expoentes aumenta.

Com o objetivo de resolver o problema nas funções peso das GTF's, Mohallem [60] acrescentou uma troca de rótulos à DI, que nada mais é do que uma mudança de escala no intervalo de integração do espaço da coordenada geradora:

$$
\Omega=\frac{\ln \alpha}{A}, A \geq 1
$$

onde A é um fator a ser determinado numericamente, e cujo valor ótimo encontrado foi 6,0 [61]. A troca de rótulos tornou possível a discretização integral das equações GW-HF usando GTF's como função geradora, pois suas funções peso tornam-se estreitas e suaves.

É importante salientar que durante o desenvolvimento da base, a malha de pontos igualmente espaçados é feita para cada simetria $w$ do sistema atômico, e é construída conforme a relação:

$$
\Omega_{k}^{(w)}=\frac{\ln \alpha_{k}^{(w)}}{6}=\Omega_{\min }^{(w)}+(k-1) \Delta \Omega^{(w)}, k=1, \ldots, N ; w=s, p, d, f, \text { etc } .
$$

Na equação (3.48), N é o número de pontos de discretização e $\Omega_{\min }^{(w)}$ e $\Delta \Omega^{(w)}$ são, respectivamente, o primeiro ponto da malha e o incremento usado para obter os pontos subsequentes. O número de pontos da malha determina o tamanho da base. O menor $\left(\Omega_{\min }^{(w)}\right)$ e o maior $\left(\Omega_{\max }^{(w)}\right.$ ) ponto da malha $\Omega_{k}^{(w)}$ são escolhidos de modo que se abranja faixas de integração adequadas para as funções peso $f_{k}$. A aplicação da DI nas equações GW-HF gera 
um conjunto $\left\{\Omega_{i}\right\}$ e, em simultâneo, um conjunto de expoentes $\left\{\alpha_{i}\right\}$ com o qual se constroi os conjuntos de base.

\subsubsection{A Discretização Integral Polinomial}

Em relação à DI, a condição dos espaços numéricos na malha serem igualmente espaçados, apesar de ser prática em fazer a integração numérica, sempre impôs alguma restrição na geração dos expoentes. Para átomos leves (pertencentes a primeira e segunda fila da tabela periódica), o método da coordenada geradora nunca foi hábil em gerar bases precisas de tamanho pequeno ou médio com funções gaussianas [62].

Com o intuito de contornar as limitações da DI, Barbosa e da Silva [63] propuseram uma nova discretização através de uma expansão polinomial da equação (3.48), conferindo-a a forma:

$$
\Omega_{k}^{(w)}=\frac{\ln \alpha_{k}^{(w)}}{6}=\Omega_{\text {min }}^{(w)}+\Delta \Omega_{1}^{(w)}(k-1)+\Delta \Omega_{2}^{(w)}(k-1)^{2}+\cdots+\Delta \Omega_{q}^{(w)}(k-1)^{q}
$$

onde $\mathrm{k}=1,2, \ldots, \mathrm{N}$ e $w=\mathrm{s}, \mathrm{p}, \mathrm{d}, \mathrm{f}$, etc.

Dessa forma, os expoentes $\alpha$ das funções de onda GTF's serão encontrados por meio da seguinte relação:

$$
\alpha_{k}^{(w)}=\exp 6\left\{\Omega_{\min }^{(w)}+\Delta \Omega_{1}^{(w)}(k-1)+\Delta \Omega_{2}^{(w)}(k-1)^{2}+\cdots+\Delta \Omega_{q}^{(w)}(k-1)^{q}\right\}
$$

Esta nova abordagem recebeu o nome de Discretização Integral Polinomial (DIP) e possui a primazia de gerar conjuntos de bases mais flexíveis, sem comprometer a qualidade de

seus resultados. Os incrementos $\Delta \Omega_{q}^{(w)}$ devem ser determinados variacionalmente, e vão depender do grau do polinômio. Neste trabalho, os polinômios da malha foram truncados ao terceiro grau.

O processo de construção dos conjuntos de primitivas através do ATOM-SCF é definida pelas condições impostas no input do programa, como o elemento químico, o estado eletrônico, a carga e o tamanho das bases. Outro dado importante reside no chute inicial dos incrementos para a construção da malha, que foram obtidos pelo ajuste polinomial de diversas funções de base da literatura, utilizando o ORIGIN [64]. Durante o trabalho, vários tamanhos de conjuntos foram testados, sendo utilizado o critério variacional para o desenho das bases. As energias de referência foram obtidas dos resultados HF numéricos fornecidos por Koga e 
colaboradores [65]. O tamanho ótimo adotado para os conjuntos de base foi $18 s 13 p$, por apresentarem energias excelentes em relação à energia HF numérica. A adição de mais funções $s$ e $p$ demonstrou-se ineficiente, indicando que os conjuntos de primitiva alcançaram o ponto de saturação HF.

\subsection{Contração dos Conjuntos de Base}

A contração dos conjuntos de base foi feita pelo método da contração geral de Raffenetti [42], para produzir conjuntos de qualidade sêxtuplo-zeta de valência. Os coeficientes das funções contraídas foram determinados por um cálculo HF. Para cada conjunto as 5 primitivas mais difusas permaneceram descontraídas. Em seguida aplicou-se as considerações de Hashimoto et al. [46], onde os autores propõem que as primitivas não contraídas no esquema de Raffenetti poderiam ser eliminadas das funções contraídas sem qualquer perda de energia. Ao termino das contrações, os conjuntos de base foram reduzidos de $(18 s 13 p)$ primitivas para [7s6p].

\subsection{Polarização dos Conjuntos de Base}

Para todos os conjuntos de base dos átomos e dos ânions, foram testados dois tipos de polarização: $4 d 3 f 2 g$ e $4 d 3 f 2 g l h$. Os expoentes são obtidos através de um programa que utiliza o algoritmo SIMPLEX [47] na determinação dos expoentes ótimos para o cálculo CISD de cada espécie. O método SIMPLEX é uma técnica amplamente utilizada para se determinar, numericamente, a solução ótima de um modelo em programação linear. Neste caso, o SIMPLEX é adaptado para resolver um problema de minimização (da energia eletrônica CISD). Durante o processo de otimização, todos os expoentes são variados por incrementos que devem ser definidos cuidadosamente, pois incrementos muito pequenos podem limitar seu resultado à um poço de mínimo local, enquanto incrementos muito grandes podem negligenciar pontos ou regiões próximas ao mínimo absoluto. A otimização dos expoentes consiste em nove e dez variáveis (referentes às polarizações $4 d 3 f 2 g$ e $4 d 3 f 2 g l h$ ) a serem otimizadas. O processo da otimização pode ser compreendido como um ponto que caminha numa superfície potencial de nove ou dez dimensões, em busca do mínimo absoluto, onde em cada passo é feito um cálculo CISD para determinar a energia do sistema. Devido ao número de passos requeridos para cada otimização, ao tamanho da base e ao nível de teoria utilizado, esta foi a etapa mais demorada do trabalho. 
Ao final do processo de polarização, foram formados para cada elemento $(\mathrm{B}, \mathrm{C}, \mathrm{O}, \mathrm{F})$, quatro conjuntos distintos de bases:

6ZMCG-NT4d3f2g: conjunto de base desenvolvido em ambiente atômico, de polarização $4 d 3 f 2 g$.

6ZMCG-NT4d3f2g1h: conjunto de base desenvolvido em ambiente atômico, de polarização $4 d 3 f 2 g 1 h$.

6ZMCG-ION4d3f2g: conjunto de base desenvolvido em ambiente aniônico, de polarização $4 d 3 f 2 g$.

6ZMCG-ION4d3f2g1h: conjunto de base desenvolvido em ambiente aniônico, de polarização $4 d 3 f 2 g l h$.

Todos os conjuntos de base aqui utilizados estão disponíveis para consulta no apêndice desta dissertação.

\subsection{Avaliação dos Conjuntos de base: Cálculo das Afinidades Eletrônicas}

Todos os cálculos de estrutura eletrônica foram calculados utilizando o programa GAUSSIAN 09 [48]. As afinidades atômicas foram calculadas conforme sua própria definição como exposto a seguir.

\subsubsection{Afinidade Eletrônica Atômica}

Para o caso atômico, a afinidade eletrônica de um átomo X qualquer é simplesmente a diferença das energias totais $E_{\text {tot }}$ nos estados fundamentais de $\mathrm{X}$ e seu respectivo ânion $\mathrm{X}^{-}$:

$$
A E(X)=E_{\text {tot }}(X)-E_{\text {tot }}\left(X^{-}\right)
$$

As energias do estado fundamental para o átomo e seu ânion foram calculadas em nível QCISD(T), levando em conta todos os elétrons para o calculo da correlação. Como mencionado na introdução deste trabalho, as AEs são calculadas convencionalmente utilizando o mesmo conjunto de base para descrever ambas as espécies. Na literatura não existem estudos sobre a aplicação de bases desenvolvidas pelo MCG-HF via DIP na predição de afinidades eletrônicas. Deste modo, as afinidades eletrônicas serão calculadas de três maneiras distintas:

1) AE(d-d): ambas as espécies foram descritas pela base difusa, modo convencional; 
2) $\mathrm{AE}(n-n)$ : ambas as espécies foram descritas por uma base "neutra":

3) AE(n-d): a espécie neutra é descrita pela base neutra e seu respectivo ânion é descrito pela nossa base difusa.

\subsubsection{Afinidade Eletrônica Molecular}

O conceito do cálculo teórico das afinidades eletrônicas moleculares não é tão direto quanto no caso dos átomos. A progressão de átomo para moléculas é acompanhada de complicações, causadas principalmente pelo maior grau de liberdade apresentado pelas moléculas. Por esta razão, a afinidade eletrônica para uma molécula $M$ é a energia de transição do estado fundamental vibracional/rotacional do ânion para o estado fundamental vibracional/rotacional da espécie neutra (figura 1).

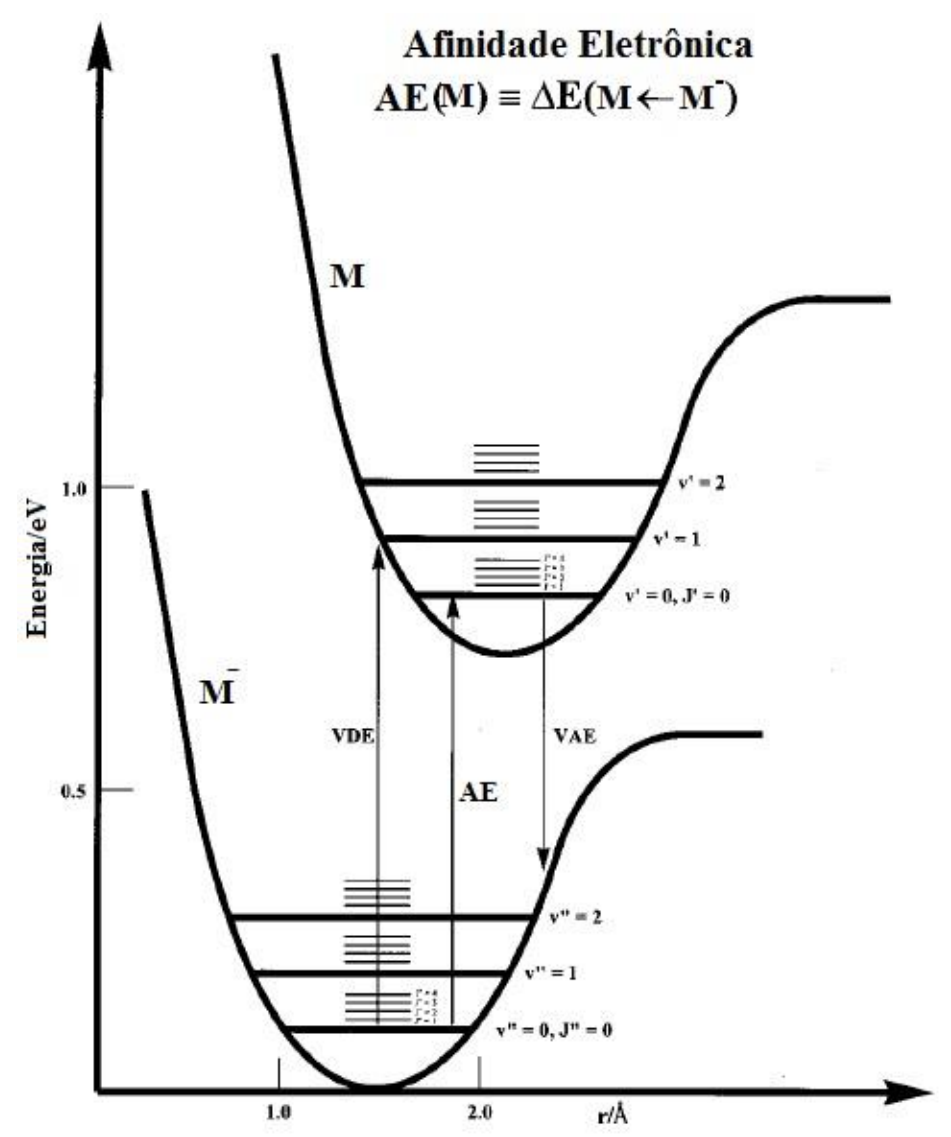

Figura 1. Diagrama qualitativo das superfícies de energia potencial para uma molécula M e seu respectivo ânion M-. Imagem adaptada de Rienstra-Kiracofe [12].

Em geral, o processo em que o elétron se liga à uma molécula é acompanhado pela mudança na configuração nuclear da mesma. Desta maneira, são necessários outros conceitos para tratar das transformações energéticas envolvendo transferências eletrônicas, como a 
afinidade eletrônica adiabática (AEA), a vertical detachment energy (VDE) e a vertical attachment energy (VAE). As energias VDE e VAE diferem da afinidade eletrônica pois se referem a diferença de energia onde uma das duas espécies (neutra e aniônica) não está em sua conformação mais estável. A afinidade eletrônica adiabática pode ser entendida como um processo infinitamente lento de adição/remoção de um elétron da molécula/ânion que modificaria a configuração nuclear por acréscimos infinitesimais, e seria equivalente à definição de afinidade eletrônica molecular. Em outras palavras, a AEA, ou simplesmente $\mathrm{AE}$, seria a diferença de energia entre a molécula neutra em sua geometria de equilíbrio e a molécula aniônica em sua geometria de equilíbrio:

$$
A E(M)=E_{\text {tot }}(M, \text { geom. eq. })-E_{\text {tot }}\left(M^{-}, \text {geom. eq. }\right)
$$

Deste modo, os cálculos moleculares foram feitos em nível QCISD em conjunto com uma otimização de estrutura, para ambas as espécies. De maneira análoga ao caso atômico, também foram calculadas AEs moleculares do tipo AE(d-d), AE(n-n) e AE(n-d).

Os resultados atômicos e moleculares de afinidade eletrônica para as bases aug-ccpVQZ, -pV5Z foram obtidos por cálculos realizados sob condições idênticas à das nossas bases.

\section{Resultados e Discussão}

\subsection{Geração dos Conjuntos de base}

Durante o processo de geração das bases, os parâmetros como os incrementos das Discretização Polinomial Integral e o número de funções de base apresentaram maior peso sobre a energia final dos conjuntos de base. Tais parâmetros eram variados no intuito de aproximar a energia HF das bases o mais próximo possível das energias de referência HF numéricos. As energias de HF numérico são usadas por estarem muito próximas do limite Hartree-Fock, definido como o valor mais baixo que pode ser obtido por uma função de onda de determinante único.

Na tabela 1 encontram-se as energias HF fornecidas no output do ATOM-SCF para os melhores conjuntos de primitivas de cada átomo e ânion, bem como as energias HF numéricas para comparação. Como se pode perceber, os conjuntos de primitiva gerados pelo MCGHF/DIP fornecem energias bastante próximas ao HF numérico, com erros da ordem de $10^{-4}$ a $10^{-5}$ hartrees, com exceção da base para o $\mathrm{O}^{-}$que apresentou erro da ordem de $10^{-3}$ hartree, 
ainda bastante próximo do valor de referência. Estes resultados sugerem que nossa metodologia MCG-HF/DIP está qualificada a gerar conjuntos de base que reproduzem muito bem a energia de sistemas tanto neutros quanto aniônicos em nível HF.

Tabela 1: Energias Hartree-Fock obtidas com o conjunto de primitivas para os átomos neutros e seus ânions.

\begin{tabular}{|c|c|c|c|c|}
\hline Espécie & Estado & $\begin{array}{c}\text { Tamanho da } \\
\text { base }\end{array}$ & Energia $H F^{a}$ & $\begin{array}{l}\text { Energia } H F \\
\text { numérica }^{a, b}\end{array}$ \\
\hline$B$ & ${ }^{2} P$ & $18 \mathrm{~s} 13 \mathrm{p}$ & $-24,5290222$ & $-24,5290607$ \\
\hline$B^{-}$ & ${ }^{3} P$ & $18 \mathrm{~s} 13 \mathrm{p}$ & $-24,5192071$ & $-24,5192214$ \\
\hline$C$ & ${ }^{3} P$ & $18 \mathrm{~s} 13 \mathrm{p}$ & $-37,6877458$ & $-37,6886190$ \\
\hline$C^{-}$ & ${ }^{4} S$ & $18 \mathrm{~s} 13 \mathrm{p}$ & $-37,7086410$ & $-37,7088436$ \\
\hline$O$ & ${ }^{3} P$ & $18 \mathrm{~s} 13 \mathrm{p}$ & $-74,8090444$ & $-74,8093985$ \\
\hline$O^{-}$ & ${ }^{2} P$ & $18 \mathrm{~s} 13 \mathrm{p}$ & $-74,7866743$ & $-74,7897459$ \\
\hline$F$ & ${ }^{2} P$ & $18 s 13 p$ & $-99,4092801$ & $-99,4093494$ \\
\hline$F^{-}$ & ${ }^{1} S$ & $18 s 13 p$ & $-99,4594474$ & $-99,4594539$ \\
\hline
\end{tabular}

\subsection{Cálculos de Afinidade Eletrônica Atômica}

Após a geração das primitivas para o conjunto, as bases foram contraídas e então polarizadas gerando quatro tipos distintos de conjuntos: 6ZMCG-NT4d3f2g, 6ZMCGNT4d3f2g1h, 6ZMCG-ION4d3f2g e 6ZMCG-ION4d3f2g1h. A nomenclatura é intuitiva, 6Z denota que a base têm qualidade sêxtuplo-zeta de valência, o MCG refere-se ao método com o qual a base foi desenvolvida. O NT e ION indicam respectivamente se a base foi otimizada em ambiente neutro, ou se foi otimizada em ambiente aniônico. Por fim, 4d3f2g e 4d3f2g1h indicam a polarização dos conjuntos.

Os resultados dos cálculos das afinidades eletrônicas estão separados de acordo com a polarização da base utilizada, e subdividido conforme os métodos de cálculo (n/n), (d/d) e (n/d). A figura 2 apresenta um diagrama didático de como cada uma das afinidades eletrônicas foi estimada. Nas tabelas 2 e 3, encontram-se calculadas pelo método HartreeFock as AEs utilizando as bases polarizadas em $4 d 3 f 2 g$ e $4 d 3 f 2 g l h$, respectivamente. 


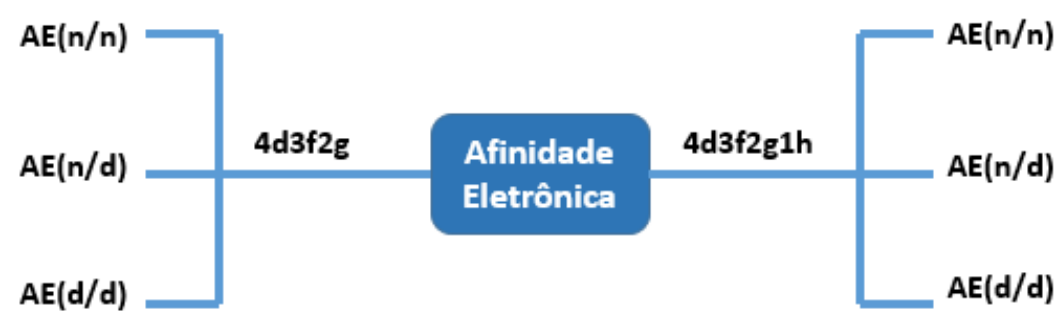

Onde:

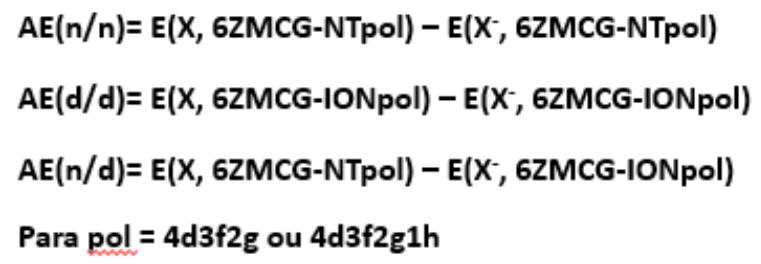

Figura 2. Esquema de cálculos para as afinidades eletrônicas.

Os resultados da tabela 2 confirmam que o método HF é absolutamente inapropriado para o cálculo de afinidades eletrônica, mesmo do ponto de vista qualitativo, a julgar que apenas o carbono e o flúor apresentaram afinidades eletrônicas positivas. Aparentemente, em nível de cálculo HF, o modo como a $\mathrm{AE}$ é calculada exerce pouca influência sobre seu resultado. Este comportamento pode ser explicado pela ausência de correlação eletrônica no cálculo HF, o que propicia uma espécie de efeito gargalo, onde ambos os conjuntos de base neutro e difuso tendem ao limite HF das espécies neutra e carregada.

Tabela 2: Resultados para afinidades eletrônicas calculadas pelo método Hartree-Fock utilizando os conjuntos de polarização $4 d 3 f 2 g$.

\begin{tabular}{|c|c|c|c|c|c|}
\hline & \multicolumn{5}{|c|}{$A E(e V)-H F$} \\
\hline Átomo & $(\mathrm{n} / \mathrm{n})$ & $(d / d)$ & $(\mathrm{n} / \mathrm{d})$ & Numérica $^{a}$ & Experimental $^{b, c}[12]$ \\
\hline$B$ & $-0,323$ & $-0,304$ & $-0,304$ & $-0,268$ & 0,280 \\
\hline$C$ & 0,439 & 0,452 & 0,451 & 0,550 & 1,262 \\
\hline$O$ & $-0,601$ & $-0,574$ & $-0,575$ & $-0,535$ & 1,461 \\
\hline$F$ & 1,164 & 1,175 & 1,175 & 1,363 & 3,401 \\
\hline $\begin{array}{l}a \text { Diferença } \\
\text { experimentai } \\
\text { de } 10^{-5} \text { a } 10^{-7} \text {. }\end{array}$ & $\begin{array}{l}\text { s ener } \\
\text { obtido }\end{array}$ & numé & ntre a & $\begin{array}{l}\text { neutra e } \\
\text { os erros ex }\end{array}$ & $\begin{array}{l}\text { ânion. }{ }^{b} \text { Os resultados } \\
\text { mentais foram da ordem }\end{array}$ \\
\hline
\end{tabular}


Tabela 3: Resultados para afinidades eletrônicas calculadas pelo método Hartree-Fock utilizando os conjuntos de polarização $4 d 3 f 2 g l h$.

$A E(e V)-H F$

\begin{tabular}{c|cccc} 
Átomo & $(\mathrm{n} / \mathrm{n})$ & $(\mathrm{d} / \mathrm{d})$ & $(\mathrm{n} / \mathrm{d})$ & Experimental [12] \\
$B$ & $-0,323$ & $-0,304$ & $-0,304$ & 0,280 \\
$C$ & 0,439 & 0,452 & 0,451 & 1,262 \\
$O$ & $-0,601$ & $-0,574$ & $-0,575$ & 1,461 \\
$F$ & 1,164 & 1,175 & 1,175 & 3,401
\end{tabular}

Os resultados da tabela 3 corroboram com a observação feita no parágrafo anterior, pois a adição de uma função de simetria $h$ aos conjuntos não provocou mudanças significativas nas afinidades eletrônicas pelo método HF (foram observadas mudanças apenas na quarta casa decimal).

Como esperado, o método HF mostrou-se inadequado para se obter qualquer conclusão relacionado a qualidade das bases deste trabalho no que concerne o cálculo acurado de afinidades eletrônicas. Desta maneira, optou-se por utilizar uma metodologia mais refinada e a escolha recaiu sobre o método CI truncado por ser variacional, o que é importante quando se trata de uma propriedade calculada algebricamente a partir das energias eletrônicas. Além disso, Feller e Davidson [67] demonstraram que os métodos CC e MPPT tendem a superestimar as afinidades eletrônicas em até $0,1 \mathrm{eV}$. Na tabela 4 estão os resultados de AEs calculados em nível QCISD(T) para as bases de polarização $4 d 3 f 2 g$.

Tabela 4: Resultados para afinidades eletrônicas calculadas em nível QCISD(T) utilizando os conjuntos de polarização $4 d 3 f 2 g$.

$$
A E(e V)-Q C I S D(T)
$$

\begin{tabular}{c|cccc}
\hline Átomo & $(\mathrm{n} / \mathrm{n})$ & $(\mathrm{d} / \mathrm{d})$ & $(\mathrm{n} / \mathrm{d})$ & Experimental [12] \\
$B$ & 0,007 & 0,256 & 0,029 & 0,280 \\
$C$ & 1,204 & 1,248 & 1,034 & 1,262 \\
$O$ & 1,324 & 1,415 & 1,141 & 1,461 \\
$F$ & 3,323 & 3,385 & 3,131 & 3,401 \\
\hline
\end{tabular}


Os dados expostos na tabela 4 confirmam a importância da correlação eletrônica para o cálculo de AEs. Como apontado por Blondel [68], a existência de íons negativos depende significativamente da correlação instantânea no movimento dos elétrons. Para todos os casos as afinidades eletrônicas saíram positivas. É notável a melhora dos resultados, que agora podem ser interpretados quantitativamente, à exceção do boro, cujas EAs para os casos (n/n) e (n/d) tiveram resultados inferiores. Com relação ao modo de se calcular afinidade eletrônica, percebe-se que os melhores resultados são obtidos quando se utiliza o mesmo conjunto de base, apoiando a afirmação feita por Schaefer III de que AEs acuradas só são obtidas pelo uso do mesmo conjunto de base para descrever ambas espécies neutra e aniônica.

Da tabela 4 também se percebe que os resultados mais próximos do experimental foram obtidos pelo uso das funções intrinsicamente difusas, desenvolvidas em ambiente aniônico pelo método da coordenada geradora, a principal ideia deste trabalho. Por exemplo, para o boro, as funções mais difusas de simetria $s$ e $p$ possuem expoentes 0,05661730 e 0,03298239, respectivamente, enquanto que para o ânion $\mathrm{B}^{-}$as funções mais difusas $s$ e $p$ têm como expoentes 0,02735899 e 0,00651538. O êxito destes conjuntos de base deve-se principalmente a melhor capacidade de descrever os elétrons em regiões mais afastadas do núcleo. Adicionalmente, é muito provável que estes conjuntos sejam capazes de recuperar a energia de correlação do átomo e de seu ânion em taxas semelhantes.

Tabela 5: Resultados para afinidades eletrônicas calculadas em nível QCISD(T) utilizando os conjuntos de polarização $4 d 3 f 2 g l h$.

$$
A E(e V)-Q C I S D(T)
$$

\begin{tabular}{c|cccc}
\hline Átomo & $(\mathrm{n} / \mathrm{n})$ & $(\mathrm{d} / \mathrm{d})$ & $(\mathrm{n} / \mathrm{d})$ & Experimental [12] \\
$B$ & 0,202 & 0,258 & 0,031 & 0,280 \\
$C$ & 1,206 & 1,251 & 1,037 & 1,262 \\
$O$ & 1,324 & 1,424 & 1,149 & 1,461 \\
$F$ & 3,331 & 3,394 & 3,139 & 3,401 \\
\hline
\end{tabular}

Como se pode perceber na tabela 5 , a adição da função de simetria $h$ ocasiona uma pequena melhora nos resultados, geralmente alterando os valores de AE na terceira casa decimal, a única exceção é para o caso do boro, em que a função adicional faz o valor da AE $(\mathrm{n} / \mathrm{n})$ ir de 0,007 para 0,202. Para este cálculo, o conjunto neutro deve ser o responsável por 
descrever insatisfatoriamente o ânion $\mathrm{B}^{-}$, de modo que a função de polarização $h$ apresentouse mais energeticamente importante para o ânion do que para a espécie neutra.

Para uma melhor análise comparativa, as bases 6ZMCG-ION4d3f2g e 6ZMCGION4d3f2g1h tiveram seus resultados expostos em conjunto com o das bases aug-cc-pVQZ, pV5Z (tabela 6). Os conjuntos deste trabalho apresentam desempenho melhor ou equivalente ao apresentado pelas bases do Dunning para o boro e carbono. Por outro lado, a aug-cc-pVQZ apresentou excelente concordância com o resultado experimental para o flúor, enquanto que a aug-cc-pV5Z superestimou a afinidade eletrônica em 0,02 eV. Para as bases difusas a adição da função $h$ teve muito pouca influência na AE para o boro, indicando que a base está muito próxima do seu ponto de saturação. Por outro lado, observou-se incrementos absolutos cada vez maiores à medida que se vai do carbono para o flúor, o que é compreensível visto que mais funções são necessárias para recuperar a energia de correlação conforme o número de elétrons do sistema cresce.

Tabela 6: Comparativo entre as AEs obtidas com as bases 6ZMCG-ION (4d3f2g e 4d3f2g1h), aug-cc-pVQZ e aug-cc-pV5Z.

\begin{tabular}{c|cc|c|c|c}
\multicolumn{7}{c}{$A E(\mathrm{eV})-Q C I S D(T)$} \\
\hline Átomo & $\begin{array}{c}\text { 6ZMCG- } \\
\text { ION4d3f2g }\end{array}$ & $\begin{array}{c}\text { 6ZMCG- } \\
\text { ION4d3f2g1h }\end{array}$ & aug-cc-pVQZ & aug-cc-pV5Z & Experimental [12] \\
$B$ & 0,256 & 0,258 & 0,250 & 0,256 & 0,280 \\
$C$ & 1,248 & 1,251 & 1,248 & 1,255 & 1,262 \\
$O$ & 1,415 & 1,424 & 1,418 & 1,442 & 1,461 \\
$F$ & 3,385 & 3,394 & 3,401 & 3,421 & 3,401
\end{tabular}

Para os conjuntos de base difusos, todos os cálculos resultaram em estimativas muito próximas (acima de $90 \%$ ) das medidas experimentais, como pode ser constatado na figura 3. A eficiência do conjunto 6ZMCG-ION4d3f2g1h está entre algo como os conjuntos aug-ccpVQZ e augcc-pV5Z, o que é muito bom, considerando que a aug-cc-pV5Z é um conjunto significativamente maior, contendo uma função de polarização a mais para cada simetria $(5 d 4 f 3 g 2 h)$. 


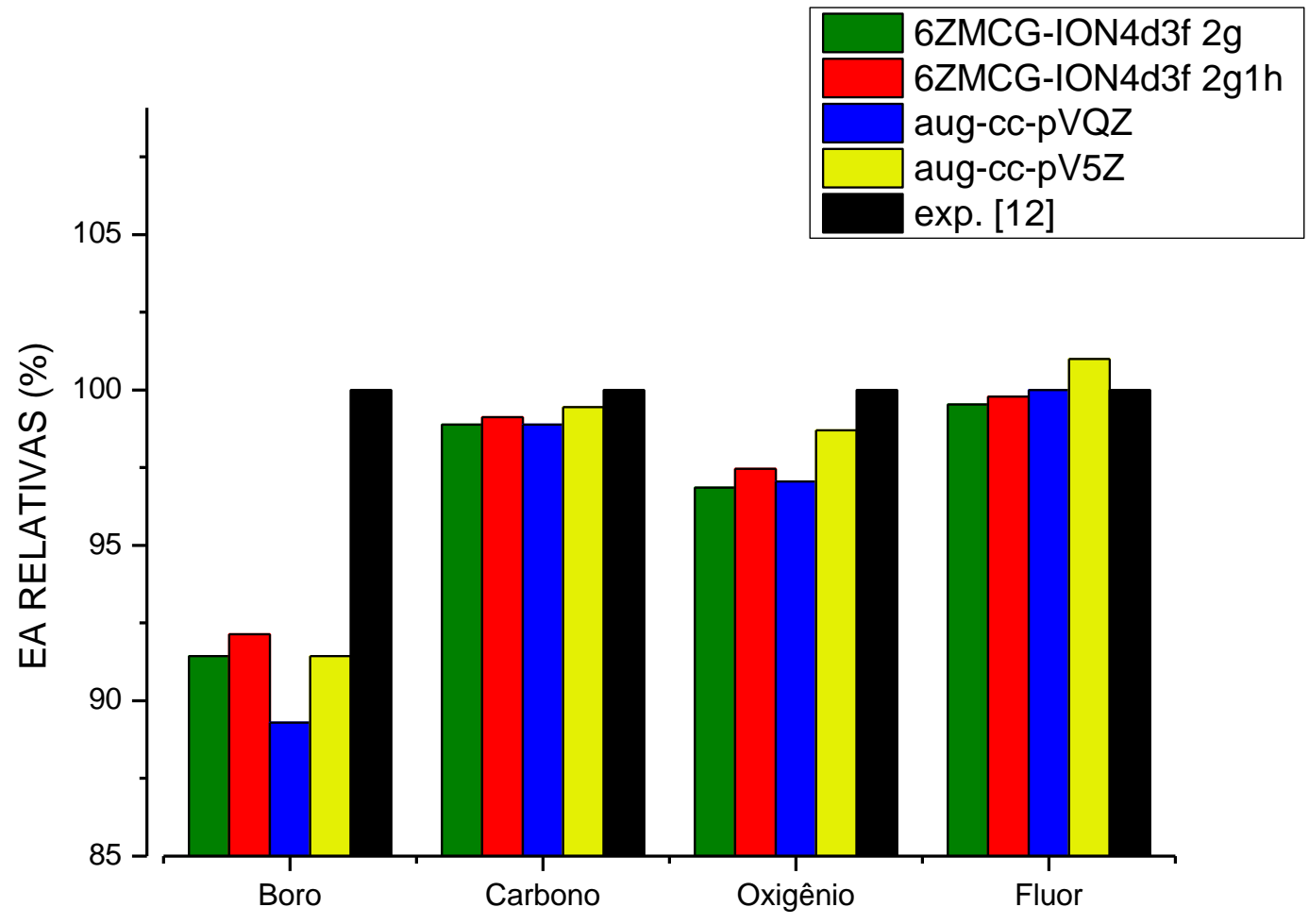

Figura 3. Comparação entre as afinidades eletrônicas relativas (\%) para os conjuntos 6ZMCG-ION4d3f2g, 6ZMCG-ION4d3f2g1h, aug-cc-pVQZ e aug-cc-pV5Z.

\subsection{Cálculos de Afinidade Eletrônica Molecular}

O modo de calcular as afinidades eletrônicas também foi avaliado para o caso molecular, mesmo sabendo que o calculo $(\mathrm{d} / \mathrm{d})$ forneceu os melhores resultados para todos os casos atômicos estudados. Infelizmente não foi possível realizar os cálculos moleculares para as bases aug-cc-pV5Z e nossas bases de polarização $4 d 3 f 2 g 1 h$, pois os cálculos apresentavam erros relativos à memória, provavelmente por conta de limitações de hardware. Os resultados para as bases MCG polarizadas em $4 d 3 f 2 g$ e aug-cc-pVQZ podem ser conferidos na tabela 7.

Novamente, as AEs (d/d) apresentaram os resultados mais próximos do experimental, enquanto que as $\mathrm{AEs}(\mathrm{n} / \mathrm{d})$ forneceram os piores resultados. Isto reforça a importância do uso do mesmo conjunto de base para descrever ambas as espécies neutra e carregada, para que não haja diferenças bruscas na recuperação da correlação eletrônica. Também pode ser notado que apesar de piores, os resultados para $\mathrm{AE}(\mathrm{n} / \mathrm{n})$ moleculares não estão tão distantes dos valores obtidos para $\mathrm{AE}(\mathrm{d} / \mathrm{d})$ (estando a diferença em geral na segunda casa decimal). 
Quando o conjunto dos resultados atômicos e moleculares é analisado, observa-se de imediato que, para as bases desenvolvidas pelo método da coordenada geradora, as funções de base difusas promovem melhoria mais significativa nos resultados para átomos.

Mesmo para o calculo atômico, as funções difusas apresentaram diferentes níveis de melhoria, por exemplo, a influência do uso das funções intrinsicamente difusas foi muito mais nítida para o boro, e menor para o caso extremo do flúor. É conhecido que para a ordem $\mathrm{B}, \mathrm{C}$, $\mathrm{O}, \mathrm{F}$, o raio atômico tende a diminuir conforme se vai de B para F [69], o que indica um campo de atração nuclear crescente nesta sequência. Desta forma, é razoável imaginar que o acréscimo de um elétron na camada de valência para os átomos citados cause uma expansão da nuvem eletrônica mais significativa quanto menor for a tendência do átomo atrair os elétrons pra próximo do núcleo. Seguindo este raciocínio e tomando os casos extremos de B e F, espera-se um aumento mais significativo na nuvem eletrônica para o boro que para o flúor. Infelizmente não há dados experimentais dos raios iônicos para os ânions monocarregados do $\mathrm{B}, \mathrm{C}$ e $\mathrm{O}$, mas supondo o raciocínio correto, pode-se inferir que os conjuntos de base difusos passam a ser mais importantes quanto maior for a expansão da nuvem eletrônica do sistema carregado em relação ao sistema neutro. Desta forma, não é espantoso que os resultados moleculares para as bases neutras tenham se aproximado mais do resultado experimental, pois a expansão eletrônica promovida pela adição de um elétron em uma molécula é bem menor, sendo a nuvem eletrônica menos sensível quanto maior for o tamanho do sistema.

Tabela 7: Resultados para afinidades eletrônicas moleculares calculadas em nível QCISD utilizando os conjuntos de polarização $4 d 3 f 2 g$ e aug-cc-pVQZ.

$$
A E(e V)-Q C I S D
$$

\begin{tabular}{|c|c|c|c|c|c|c|}
\hline Molécula & Estado & $(\mathrm{n} / \mathrm{n})$ & $(\mathrm{d} / \mathrm{d})$ & $(\mathrm{n} / \mathrm{d})$ & $\begin{array}{l}\text { aug-cc- } \\
\text { PVQZ }\end{array}$ & $\begin{array}{c}\text { Experimental } \\
{[12]}\end{array}$ \\
\hline$B O$ & $2 \Sigma$ & 2,401 & 2,423 & 2,352 & 2,426 & 2,508 \\
\hline$C_{2}$ & ${ }^{1} \Sigma_{\mathrm{g}}^{+}$ & 3,412 & 3,427 & 3,384 & 3,428 & 3,269 \\
\hline $\mathrm{O}_{2}$ & ${ }^{3} \sum_{\mathrm{g}}$ & 0,254 & 0,302 & 0,199 & 0,306 & 0,451 \\
\hline$F O$ & ${ }^{2} \Pi$ & 2,054 & 2,093 & 1,982 & 2,101 & 2,272 \\
\hline
\end{tabular}

A figura 4 apresenta um comparativo dos resultados obtidos com as bases 6ZMCGION4d3f2g e aug-cc-pVQZ. Em contraste com o caso atômico, para as afinidades eletrônicas 
moleculares a base do Dunning apresenta resultados levemente melhores, com diferenças na terceira casa decimal (tabela 7). No geral, foram alcançados resultados que reproduzem mais de $90 \%$ da afinidade eletrônica molecular, com exceção ao caso do oxigênio, onde tanto a 6ZMCG-ION4d3f2g quanto a aug-cc-pVQZ reproduziram pouco mais de $65 \%$. Outro caso curioso foi $\mathrm{C}_{2}$, em que ambas as bases superestimaram a afinidade eletrônica. Experimentalmente, a molécula $C_{2}$ apresenta um estado excitado ${ }^{3} \Pi_{u}$ que fica a apenas 0,09 $\mathrm{eV}$ acima do estado fundamental ${ }^{1} \Sigma_{\mathrm{g}}^{+}$. Acredita-se que essa condição próxima de degenerescência possa causar grandes imprecisões em métodos ab initio monorreferenciais, como é o caso do método CISD, que tem como estado de referência apenas a solução HF.

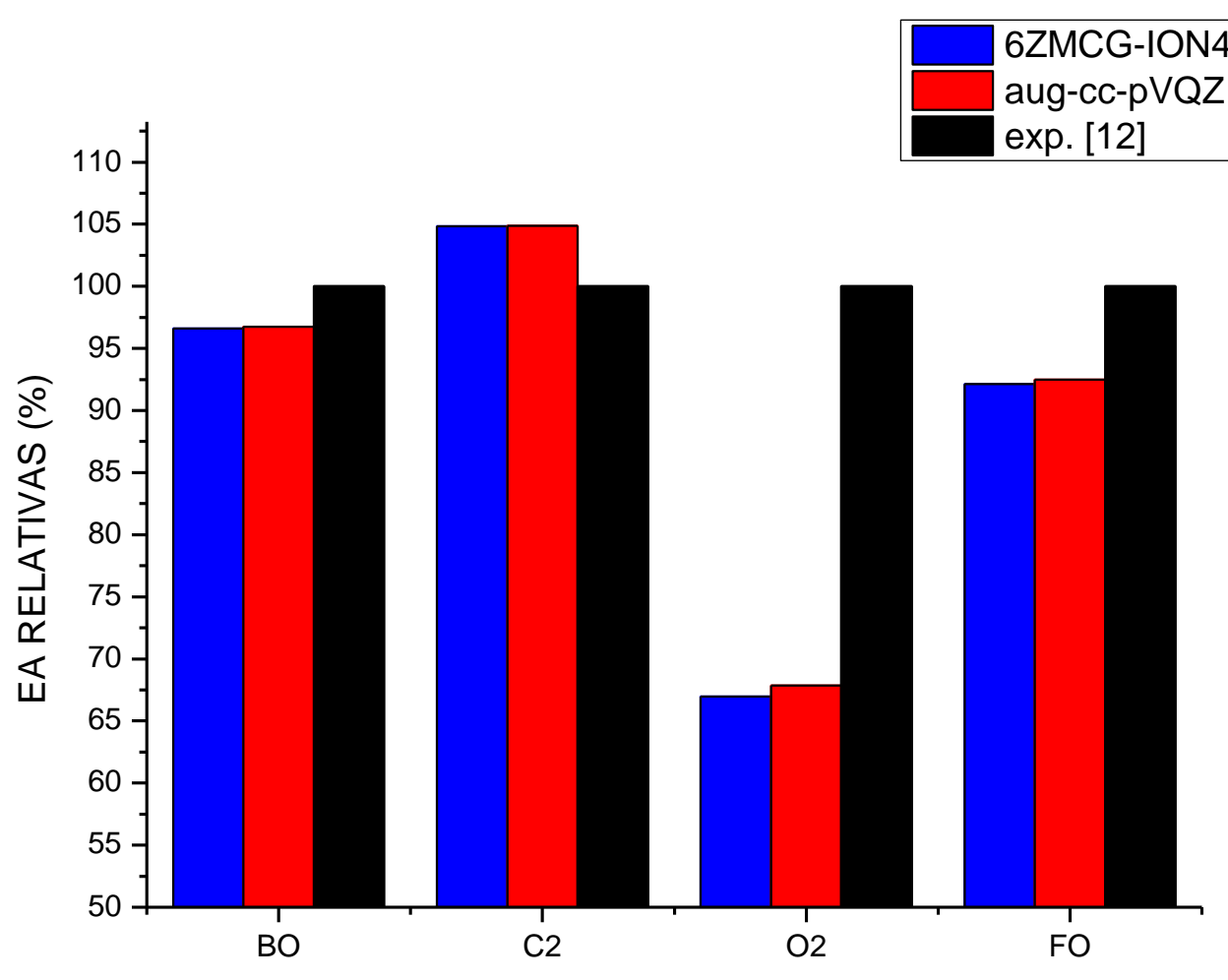

Figura 4. Comparação entre as afinidades eletrônicas relativas (\%) para os conjuntos 6ZMCG-ION4d3f2g e aug-cc-pVQZ. 


\section{Conclusões e Perspectivas Futuras}

Através do Método da Coordenada Geradora Hartree-Fock foi possível desenvolver conjuntos de bases especialmente dedicados à descrição de ânions. Ao contrário da metodologia convencional, onde a difusibilidade do conjunto de base é conferida pela adição de primitivas difusas, em nossa metodologia os conjuntos são gerados com caráter difuso intrínseco.

Os cálculos de afinidade eletrônica atômica foram feitos para os átomos B, C, O e F em nível HF e QCISD(T). Como esperado, os resultados fornecidos pelo método HF são de confiabilidade nula, pois altos níveis de correlação são necessários para reproduzir de maneira adequada a afinidade eletrônica. Os melhores resultados de afinidade eletrônica foram alcançados utilizando os conjuntos difusos 6ZMCG-ION4d3f2g e 6ZMCG-ION4d3f2g1h para descrever ambos o átomo neutro e seu ânion, como apontado por Schaefer III [12]. O desempenho dos conjuntos difusos foi semelhante ao das bases aug-cc-pVQZ e aug-cc-pVQZ, superando-os para os casos do boro e carbono. A porcentagem da afinidade eletrônica reproduzida pelo conjunto 6ZMCG-ION4d3f2g1h para os átomos B, C, O e F foi de 92,14\%, $99,13 \%, 97,47 \%$ e $99,79 \%$, respectivamente, em relação ao valor experimental. Os melhores resultados moleculares foram obtidos em nível CISD utilizando o conjunto difuso 6ZMCGION4d3f2g. A porcentagem reproduzida da afinidade eletrônica para as moléculas $\mathrm{BO}, \mathrm{C}_{2}, \mathrm{O}_{2}$ e FO foi de, respectivamente, 96,61\%, 104,83\%, 66,96\% e 92,12\%. A luz dos resultados, é provável que conjuntos intrinsicamente difusos sejam mais importantes na descrição de sistemas cuja nuvem eletrônica se expanda significativamente com o acréscimo de elétrons.

Em suma, a estratégia apresentada para a geração de bases difusas mostrou-se bastante promissora no que se refere a cálculos de afinidade eletrônica.

Como perspectivas futuras, pretendemos avaliar a eficiência das bases aqui desenvolvidas em outros tipos de propriedades moleculares e metodologias como MPPT, CCSD, DFT, e etc. Mais pesquisas devem ser feitas a fim de consolidar o conhecimento sobre o comportamento das bases difusas geradas pelo MCG. Ao que tudo indica, estas bases podem ser uteis na descrição adequada de sistemas supercarregados. O estudo da adição ou subtração de funções de polarização nos conjuntos pode ajudar a compreender o papel de cada uma destas funções para a qualidade das afinidades eletrônicas. Além disso, é necessário expandir a metodologia de geração das bases difusas para mais elementos da tabela periódica. 


\section{Referências Bibliográficas}

[1] SCIDA, K.; STEGE, P. W.; HABY, G.; MESSINA, G. A.; GARCÍA, C. D. Recent applications of carbon-based nanomaterials in analytical chemistry: Critical review. Anal. Chim. Acta 691, 6, 2011.

[2] WRIGHT, M.; UDDIN, A. Organic-inorganic hybrid solar cells: A comparative review. Sol. Energ. Mat. Sol. C. 107, 87, 2012.

[3] OMAR, A.; ABDULLAH, H. Electron transport analysis in zinc oxide-based dyesensitized solar cells: A review. Renew. Sust. Energ. Rev. 31, 149-157, 2014.

[4] TSUGAWA, K.; NODA, H.; HIROSE, K.; KAWARADA, H. Schottky barrier heights, carrier density, and negative electron affinity of hydrogen-terminated Diamond. Phys. Rev. B 81, 045303:1, 2010.

[5] ClARK, J.; ROBERTSON, J. Limits to doping in oxides. Phys. Rev. B 83, 075205:1, 2011.

[6] PICCARDO, M.; MARTINELLI, L.; IVELAND, J.; YOUNG, N.; DENBAARS, S. P.; NAKAMURA, S.; SPECK, J. S.; WEISBUCH, C.; PERETTI, J. Determination of the first satellite valley energy in the conduction band of wurtzite GaN by near-band-gap photoemission spectroscopy. Phys. Rev. B 89, 235124:1, 2014.

[7] BAUMGARTNER, T. Insights on the Design and Electron-Acceptor Properties of Conjugated Organophosphorus Materials. Acc. Chem. Res. 47, 1613, 2014.

[8] ROZNYATOVSKIY, V. V.; GARDNER, D. M.; EATON, S. W.; WASIELEWSKI, M. R. Radical Anions of Trifluoromethylated Perylene and Naphthalene Imide and Diimide Electron Acceptors. Org. Lett. 16, 696, 2014.

[9] CAPlinS, B. W.; SHEARER, A. J.; SUICH, D. E.; MULlER, E. A.; HARRIS, C. B. Measuring the electronic corrugation at the metal/organic interface. Phys. Rev. B 89, 155422:1, 2014

[10] MILLER, T. M.; FRIEDMAN, J. F.; SHUMAN, N. S.; ARD, S. G.; MELKO, J. J.; VIGGIANO, A. A. Electron Attachment to C7F14, Thermal Detachment from C7F14-, the 
Electron Affinity of C7F14, and Neutralization of C7F14- by Ar+. J. Phys. Chem. A 116, 10293, 2012.

[11] ZHANG, T.; PAPSON, K.; OCHRAN, R.; RIDGE, D. P. Stability of Flavin Semiquinones in the Gas Phase: The Electron Affinity, Proton Affinity, and Hydrogen Atom Affinity of Lumiflavin. J. Phys. Chem. A 117, 11136, 2013.

[12] RIENSTRA-KIRACOFE, J. C.; TSCHUMPER, G. S.; SCHAEFER III, H. F. Atomic and Molecular Electron Affinities: Photoelectron Experiments and Theoretical Computations. Chem. Rev. 102, 231, 2002.

[13] MALLARD, W. G.; LINSTROM, P. J., Eds. NIST Chemistry WebBook; NIST Standard Reference Database Number 69; National Institute of Standards and Technology: Gaithersburg, MD. (http://webbook.nist.gov).

[14] PEKERIS, C. L. Ground State of Two-Electron Atoms. Phys. Rev. 112, 1649, 1958.

[15] PEKERIS, C. L. $1 S^{1}, 2 S^{1}$ and $2 S^{3}$ States of $H^{-}$and of He. Phys. Rev. 126, 1470, 1962.

[16] OYLER, N. A.; ADAMOWICZ, L. Electron Attachment to Uracil. Theoretical ab Initio Study. J. Phys. Chem. 97, 11122, 1993.

[17] OYLER, N. A.; ADAMOWICZ, L. Theoretical ab initio calculations of the electron affinity of thymine. Chem. Phys. Lett. 219, 223, 1994.

[18] SANJUAN, D. R.; MERCHAN, M.; ANDRES, L. S.; RUBIO, M. Ab initio determination of the electron affinities of DNA and RNA nucleobases. J. Chem. Phys. 129, 095104:1, 2008.

[19] FABer, C.; ATtacCAlite, C.; Olevano, V.; RUnGE, E.; Blasé, X. Firstprinciples $G W$ calculations for DNA and RNA nucleobases. Phys. Rev. B 83, 115123:1, 2011.

[20] GU, J.; XIE, Y.; SCHAEFER, H. F. Benchmarking the Electron Affinity of Uracil. J. Chem. Theory Comput. 10, 609, 2014.

[21] GARDNER, N.; MAGERS, D.; HILL JR, G. Theoretical study of tautomeric and ionizing effects of guanine, cytosine, and their methyl derivatives. Struct. Chem. 25, 347, 2014. 
[22] GOEBBERT, D. J. A theoretical study of boron tetrahalides: Structures and electron affinities. Comp. Theo. Chem. 976, 201, 2011.

[23] HICKS, L. D.; FRY, A. J.; KURZWEIL, V. C. Ab initio computation of electron affinities of substituted benzalacetophenones (chalcones): a new approach to substituent effects in organic electrochemistry. Electrochimica Acta 50, 1039, 2004.

[24] BALABANOV, N. B.; PETERSON, K. A. Basis set limit electronic excitation energies, ionization potentials, and electron affinities for the $3 d$ transition metal atoms: Coupled cluster and multireference methods. J. Chem. Phys. 125, 074110:1, 2006.

[25] OSTOJIC, B. D.; DORDEVIC, D. S. The electronic properties of trimethylnaphthalenes as properties for the prediction of biodegradation rates: Ab initio and DFT study. Chemosphere 88, 91, 2012.

[26] WALlER, S. E.; RAY, M.; YODER, B. L.; JARROLD, C. C. Simple Relationship between Oxidation State and Electron Affinity in Gas-Phase Metal-Oxo Complexes. J. Phys. Chem. A 117, 13919, 2013.

[27] MARONEZE, C. M.; RAHIM, A.; FATTORI, N.; DA COSTA, L. P.; SIGOLI, F. A.; MAZALI, I. O.; CUSTÓDIO, R.; GUSHIKEM, Y. Electroactive Properties of 1-propyl-3methylimidazolium Ionic Liquid Covalently Bonded on Mesoporous Silica Surface: Development of an Electrochemical Sensor Probed for NADH, Dopamine and Uric Acid Detection. Electrochimica Acta 123, 435, 2014.

[28] SHUBINA, T. E.; SHARAPA, D. I.; SCHUBERT, C.; ZAHN, D.; HALIK, M.; KELLER, P. A.; PYNE, S. G.; JENNEPALLI, S.; GULDI, D. M.; CLARK, T. Fullerene Van der Waals Oligomers as Electron Traps. J. Am. Chem. Soc. 136, 10890-10893. 2014.

[29] TEAlE, A. M.; DE PROFT, F.; GEERLINGS, P.; TOZER, D. J. Atomic electron affinities and the role of symmetry between electron addition and subtraction in a corrected Koopmans approach. Phys. Chem. Chem. Phys. 16, 14420, 2014.

[30] TOZER, D. J.; DE PROFT, F. Computation of the Hardness and the Problem of Negative Electron Affinities in Density Functional Theory. J. Phys. Chem. A, 109, 8923, 2005.

[31] SIMONS, J. Theoretical Study of Negative Molecular Ions. Annu. Ver. Phys. Chem., 62, 107, 2011. 
[32] MORGON, N. H.; CUSTÓDIO, R. Funções de Base: O Ajuste Variacional. Chemkeys. $1,2001$.

[33] DA SILVA, A. B. F. Bases Universais Geradas Pelo Método da Coordenada Geradora Hartree-Fock e suas Aplicações em Cálculos de Propriedades Atômicas e Moleculares. 1990. Tese (Doutorado em Ciências)- Instituto de Química de São Carlos, Universidade de São Paulo, São Carlos, SP.

[34] SLATER, J. C. Atomic Shielding Constants. Phys. Rev. 36 (1), 57, 1930.

[35] BOYS, S. F. Electronic Wave Functions I. A General Method of Calculation for the Stationary States of Any Molecular System. Proc. R. Soc. 1063, 542, 1950.

[36] SHAVITT, S. Methos in Computational Physics. New York: Academic Press, 1963.

[37] SZABO, A; OSTLUND, N.S. Modern Quantum Chemistry: introduction to advanced electronic structure theory. New York: Dover,1988.

[38] EPSTEIN, S. The Variational Method. New York, 1974.

[39] LEVINE, I. N. Quantum Chemistry. New Jersey: Prentice Hall, 2000.

[40] WILSON, A. K.; WOON, D. E.;PETERSON, K. A.; T. H. DUNNING. Gaussian basis sets for use in correlated molecular calculations. IX. The atoms gallium through krypton. J. Chem. Phys. 110, 7667, 1999.

[41] DUNNING JR, T. H. Gaussian Basis Functions for Use in Molecular Calculations .1. Contration of (9s5p) Atomic Basis Sets for First-Row Atoms. J. Chem. Phys. 53, 2823, 1970. [42] RAFFENETTI, R. C. General Contraction of Gaussian Atomic Orbitals- Core, Valence, Polarization and Diffuse Basis Set- Molecular Integral Evaluation J. Chem. Phys. 58, 4452, 1973.

[43] KENDALL, R. A.; DUNNING JR, T. H.: HARRISON, R. J. Electron affinities of the first-row atoms revisited. Systematic basis sets and wave functions. J. Chem. Phys. 96, 6796, 1992.

[44] DUNNING JR, T. H. Gaussian basis sets for use in correlated molecular calculations. I. The atoms boron through neon and hydrogen. J. Chem. Phys. 90, 1007, 1989. 
[45] MORGON, N. H.; HAIDUKE, R. L. A. ATOM-SCF (modificado), 2005.

[46] HASHIMOTO, T.; HIRAO, K.; TATEWAKI, H. Comment on Dunning's CorrelationConsistent Basis sets. Chem. Phys. Lett. 243, 190, 1995.

[47] MAROS, I. Computational Techniques of the Simplex Method. Springer Science \& Business Media, 2003.

[48] Gaussian 09, Revision A.02, M. J. Frisch, G. W. Trucks, H. B. Schlegel, G. E. Scuseria, M. A. Robb, J. R. Cheeseman, G. Scalmani, V. Barone, B. Mennucci, G. A. Petersson, H. Nakatsuji, M. Caricato, X. Li, H. P. Hratchian, A. F. Izmaylov, J. Bloino, G. Zheng, J. L. Sonnenberg, M. Hada, M. Ehara, K. Toyota, R. Fukuda, J. Hasegawa, M. Ishida, T. Nakajima, Y. Honda, O. Kitao, H. Nakai, T. Vreven, J. A. Montgomery, Jr., J. E. Peralta, F. Ogliaro, M. Bearpark, J. J. Heyd, E. Brothers, K. N. Kudin, V. N. Staroverov, R. Kobayashi, J. Normand, K. Raghavachari, A. Rendell, J. C. Burant, S. S. Iyengar, J. Tomasi, M. Cossi, N. Rega, J. M. Millam, M. Klene, J. E. Knox, J. B. Cross, V. Bakken, C. Adamo, J. Jaramillo, R. Gomperts, R. E. Stratmann, O. Yazyev, A. J. Austin, R. Cammi, C. Pomelli, J. W. Ochterski, R. L. Martin, K. Morokuma, V. G. Zakrzewski, G. A. Voth, P. Salvador, J. J. Dannenberg, S. Dapprich, A. D. Daniels, O. Farkas, J. B. Foresman, J. V. Ortiz, J. Cioslowski, and D. J. Fox, Gaussian, Inc., Wallingford CT, 2009.

[49] a) HARTREE, D. R. The Wave Mechanics of an Atom with a Non-Coulomb Central Field. Part I. Theory and Methods. Proc. Cambridge Phil. Soc. 24, 89, 1928. b) FOCK, V. Näherungsmethode zur Lösung des quantenmechanischen Mehrkörperproblems. Z. Physik. 61, 126, 1930.

[50] ROOTHAAN, C. C. J. New Developments in Molecular Theory. Rev. Modern. Phys. 23, 69, 1951.

[51] MOHALLEM, J. R; DREIZLER, R. M.; TRSIC, M. Griffin-Hill-Wheeler version of Hartree-Fock equations. Int. J. Quantum Chem. Symp. 20, 45, 1986.

[52] HILL, D. L.; WHEELER, J. A. The Method of Generator Coordinates. Phys. Rev. 89, $1106,1953$.

[53] GRIFFIN J. J. WHEELER J. A. Collective Motions Nuclei by the Method of Generation Coordinates. Phys. Rev. 108, 311, 1957. 
[54] GRIFFIN, J. J. Oxygen-16 by the Method of Generator Coordinates. Phys. Rev. 108, 328, 1957.

[55] WONG, C. W. The generator-coordinate theory as a flexible formulation of the manybody Schrödinger equation. Nucl. Phys. A 147, 545, 1970.

[56] CHATTOPADHYAY, P.; DREIZLER, R. M.; TRSIC, M.; FINK, M. Illustration of the Generator Coordinate Method in Terms of Model Problems. Z. Physik 285, 7, 1978.

[57] MOHALlEM, J. R.; TRSIC, M. A case of Analytical Solution of the Griffin-HillWheeler Equation: The Ground State of the Hydrogen Atom with Gaussian Generator Function. Z. Phys. 322, 535, 1985.

[58] BROECKHOVE, J.; DEUMENS, E. A Mathematical Foundation for Discretisation Techniques in the Generator Coordinate Method. Z. Physik 292, 243, 1979.

[59] ARICKX, F.; BROECKHOVE, J.; DEUMENS, E.; VAN LEUVEN, P. Variational discretization: A new algorithm for the generator coordinate method. J. Comp. Phys. 39, 272, 1981.

[60] MOHALLEM, J. R. A Further Study on the Discretisation of the Griffin-Hill-Wheeler Equation. Z. Phys. D3, 339, 1986.

[61] CUSTÓDIO, R;GIORDAN, M.; MORGON, N. H.; GODDARD, J. D. Application of an optimization technique to the discretized version of the Griffin-Hill-Wheeler-Hartree-Fock equations. Int. J. Quantum Chem. 42, 411, 1992.

[62] DA SILVA, A. B. F.; TRSIC, M. Gaussian- and Slater-type bases for ground and certain low-lying excited states of positive and negative ions of the atoms $\mathrm{H}$ through $\mathrm{Xe}$ based on the generator coordinate Hartree-Fock method. Can. J. Chem. 74, 1526, 1996.

[63] DA SILVA, A. B. F.; BARBOSA, R. C. A new proposal for discretization of the GriffinWheeler-Hartree-Fock equations. Mol. Phys. 101, 1073, 2003.

[64] ORIGIN (OriginLab, Northampton, MA).

[65] KOGA, T.; TATEWAKI, H.; THAKKAR, A.Numerical Hartree-Fock energies of singly charged cátions and anions with $\mathrm{N} \leq 54$. J. Chem. Phys. 100, 8140, 1994. 
[66] TATEWAKI, H.; KOGA, T.; SAKAI, Y.; THAKKAR, A. J. Numerical HartreeFock energies of low-lying excited states of neutral atoms with $Z \leq 18$. J. Chem. Phys. 101, 4945, 1994.

[67] FELLER, D.; DAVIDSONM E. R. The eléctron affinity of oxygen: A systematic configuration interaction approach. J. Chem. Phys. 90, 1024, 1989.

[68] BLONDEL, C. Recent experimental achievements with negative ions. Physica Scripta T58, 31, 1995.

[69] ATKINS, P.W.; JONES, L. Princípios de química: questionando a vida moderna e o meio ambiente. 3.ed. Porto Alegre: Bookman, 2006. 


\section{APÊNDICE \\ CONJUNTOS DE BASE UTILIZADOS NESTE TRABALHO (MODELO \\ GAUSSIAN94)}

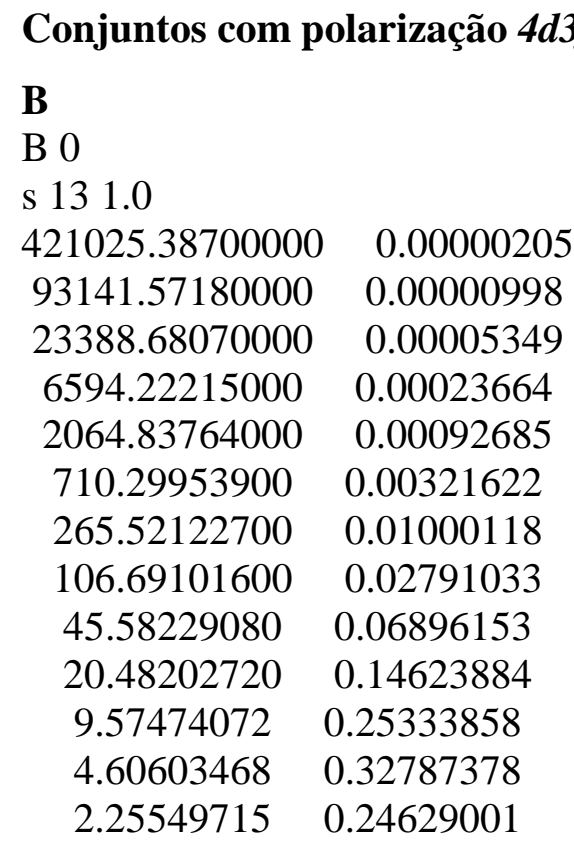

s 131.0

$\begin{array}{cl}421025.38700000 & -0.00000041 \\ 93141.57180000 & -0.00000201 \\ 23388.68070000 & -0.00001080 \\ 6594.22215000 & -0.00004779 \\ 2064.83764000 & -0.00018734 \\ 710.29953900 & -0.00065119 \\ 265.52122700 & -0.00203492 \\ 106.69101600 & -0.00574106 \\ 45.58229080 & -0.01453234 \\ 20.48202720 & -0.03230627 \\ 9.57474072 & -0.06159582 \\ 4.60603468 & -0.09919957 \\ 2.25549715 & -0.12010362 \\ \text { s } 11.0 & \\ 1.11209288 & 1.0 \\ \text { s } 11.0 & \\ 0.54612535 & 1.0 \\ \text { s } 11.0 & \\ 0.26421953 & 1.0 \\ \text { s } 11.0 & \\ 0.12457405 & 1.0 \\ \text { s } 11.0 & \\ 0.05661730 & 1.0 \\ \text { p } 81.0 & \\ 601.31753900 & 0.00001635\end{array}$




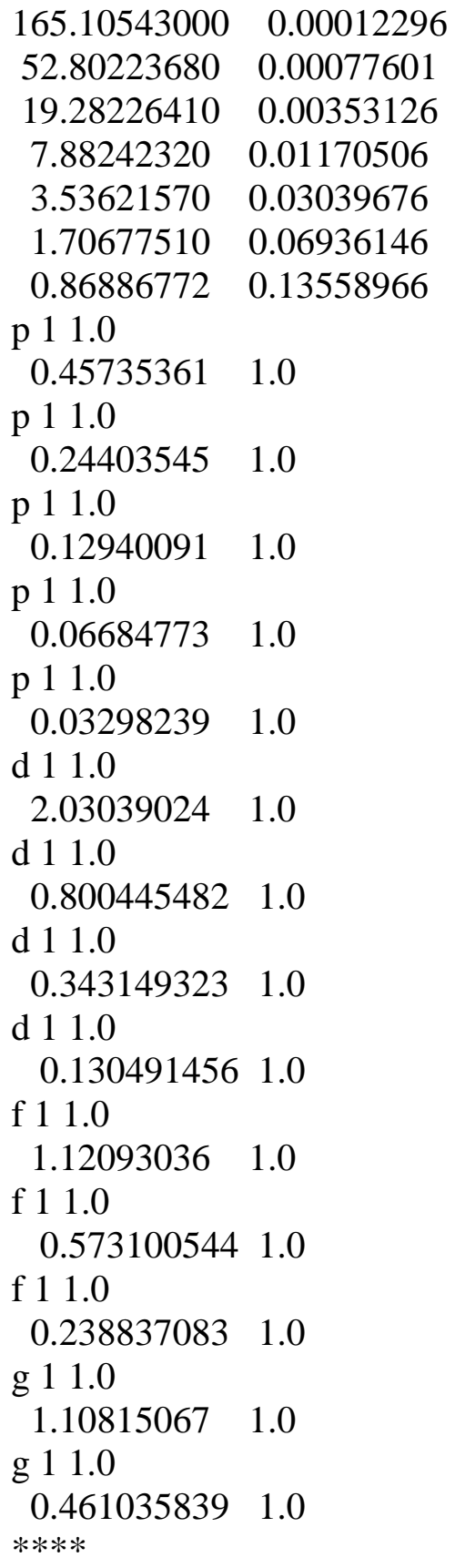




\begin{tabular}{|c|c|}
\hline 3.54952585 & 0.32461682 \\
\hline 1.71939339 & 0.17999645 \\
\hline \multicolumn{2}{|l|}{ s 131.0} \\
\hline 367567.2180000 & $0 \quad 0.00000048$ \\
\hline 73676.25230000 & 0.00000273 \\
\hline 17302.31920000 & 0.00001546 \\
\hline 4686.81132000 & 0.00007093 \\
\hline 1441.64159000 & 0.00027969 \\
\hline 495.74020400 & 0.00095654 \\
\hline 187.61964400 & 0.00289733 \\
\hline 76.93786350 & 0.00780510 \\
\hline 33.65502450 & 0.01871656 \\
\hline 15.46030280 & 0.03903104 \\
\hline 7.34268164 & 0.07049423 \\
\hline 3.54952585 & 0.10600697 \\
\hline 1.71939339 & 0.10541577 \\
\hline \multicolumn{2}{|c|}{ s 11.0} \\
\hline 0.82163654 & 1.0 \\
\hline \multicolumn{2}{|l|}{ s 11.0} \\
\hline 0.38132401 & 1.0 \\
\hline \multicolumn{2}{|l|}{ s 11.0} \\
\hline 0.16921108 & 1.0 \\
\hline \multicolumn{2}{|c|}{ s 11.0} \\
\hline 0.07067958 & 1.0 \\
\hline \multicolumn{2}{|l|}{ s 11.0} \\
\hline 0.02735899 & 1.0 \\
\hline \multicolumn{2}{|c|}{ p 81.0} \\
\hline 303.40638600 & 0.00003863 \\
\hline 91.71370010 & 0.00023730 \\
\hline 31.07298260 & 0.00135861 \\
\hline 11.59129240 & 0.00569799 \\
\hline 4.67672609 & 0.01824757 \\
\hline 2.00481418 & 0.04977532 \\
\hline 0.89699371 & 0.11598577 \\
\hline 0.41147998 & 0.20474331 \\
\hline \multicolumn{2}{|l|}{$\mathrm{p} 11.0$} \\
\hline 0.19011353 & 1.0 \\
\hline \multicolumn{2}{|l|}{ p 11.0} \\
\hline 0.08690471 & 1.0 \\
\hline \multicolumn{2}{|l|}{ p 11.0} \\
\hline 0.03861007 & 1.0 \\
\hline \multicolumn{2}{|l|}{ p 11.0} \\
\hline 0.01637743 & 1.0 \\
\hline \multicolumn{2}{|l|}{ p 11.0} \\
\hline 0.00651538 & 1.0 \\
\hline d 11.0 & \\
\hline 1.17579387 & 1.0 \\
\hline d 11.0 & \\
\hline 0.464113299 & 1.0 \\
\hline
\end{tabular}




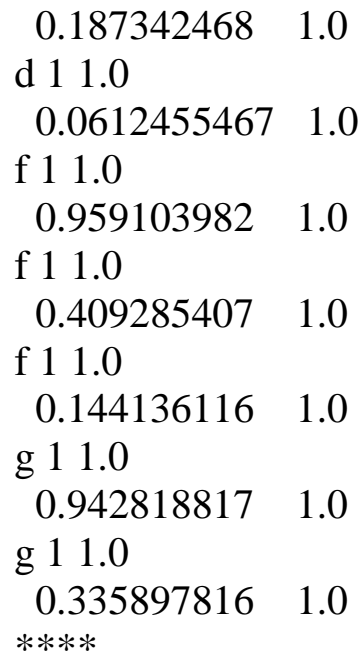




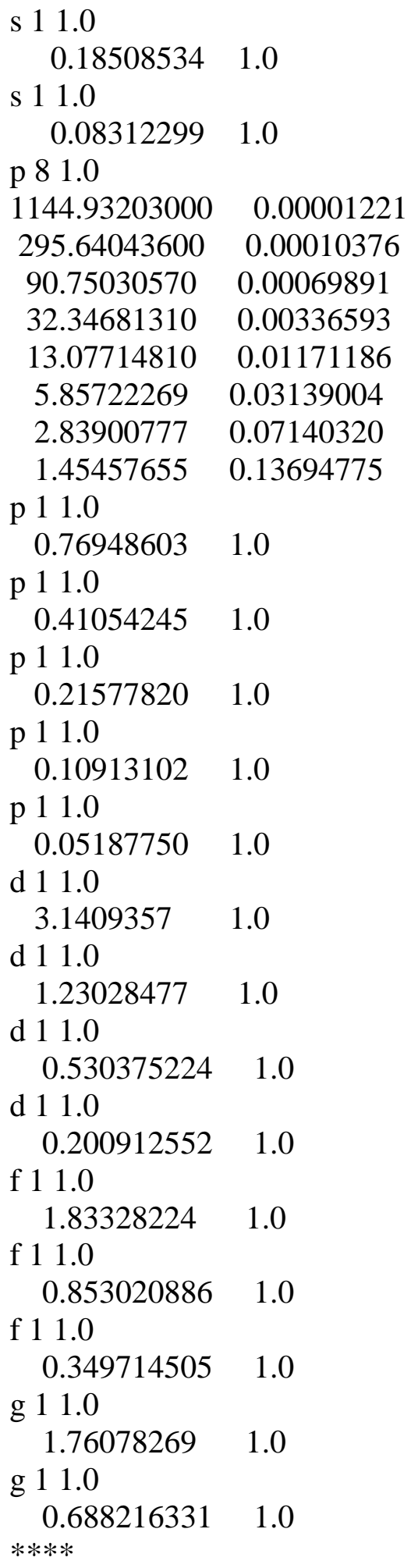




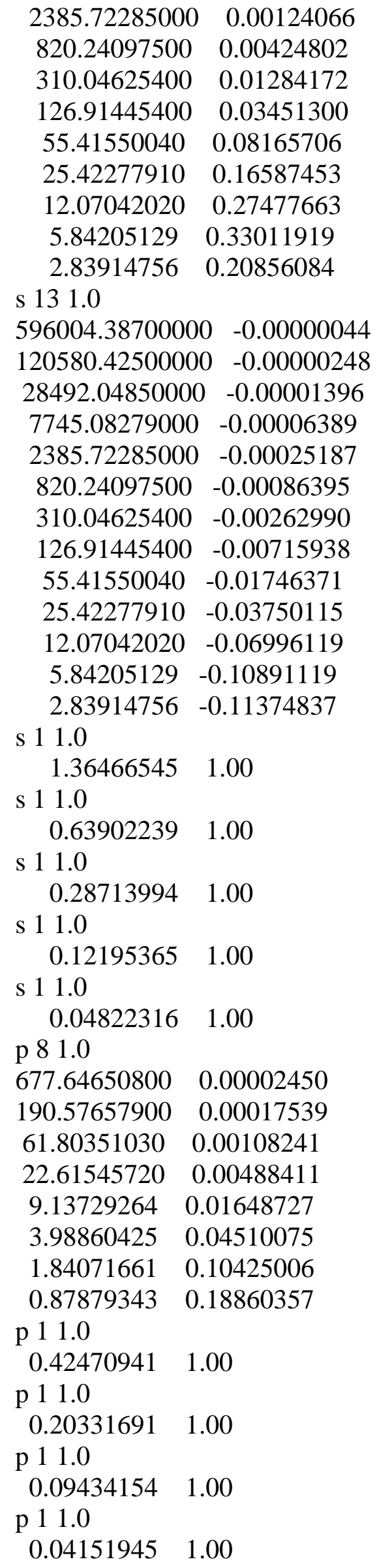




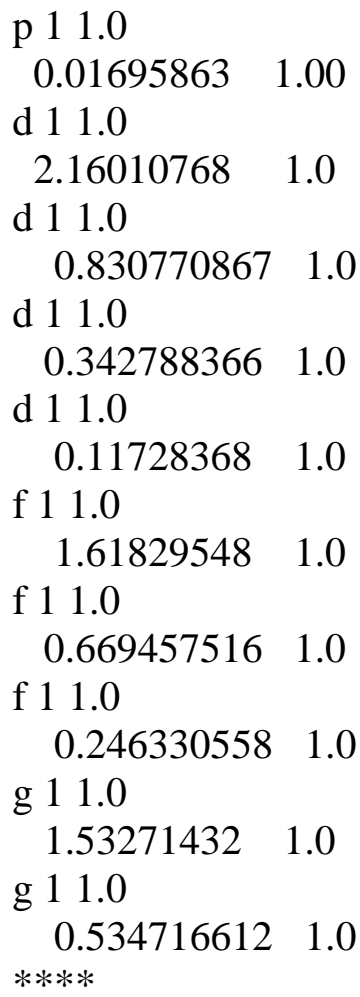




\begin{tabular}{|c|c|}
\hline 27.22845320 & -0.06800395 \\
\hline 13.11267670 & -0.11276256 \\
\hline 6.41104467 & -0.13205390 \\
\hline \multicolumn{2}{|l|}{ s 11.0} \\
\hline 3.14497838 & 1.0 \\
\hline \multicolumn{2}{|l|}{ s 11.0} \\
\hline 1.52981982 & 1.0 \\
\hline \multicolumn{2}{|l|}{ s 11.0} \\
\hline 0.72925432 & 1.0 \\
\hline \multicolumn{2}{|l|}{ s 11.0} \\
\hline 0.33667912 & 1.0 \\
\hline \multicolumn{2}{|l|}{ s 11.0} \\
\hline 0.14877644 & 1.0 \\
\hline \multicolumn{2}{|l|}{ p 81.0} \\
\hline 1997.72792000 & 0.00001441 \\
\hline 542.09009400 & 0.00011109 \\
\hline 172.51372700 & 0.00071385 \\
\hline 62.95694980 & 0.00339190 \\
\hline 25.76216240 & 0.01215286 \\
\hline 11.55820370 & 0.03421117 \\
\hline 5.559279960 & 0.08006068 \\
\hline $2.80296516 \quad 0$ & 0.15202173 \\
\hline \multicolumn{2}{|l|}{ p 11.0} \\
\hline $1.44856700 \quad 1$ & 1.0 \\
\hline \multicolumn{2}{|l|}{ p 11.0} \\
\hline $0.75029488 \quad 1$ & 1.0 \\
\hline \multicolumn{2}{|l|}{ p 11.0} \\
\hline $0.38084537 \quad 1$ & 1.0 \\
\hline \multicolumn{2}{|l|}{ p 11.0} \\
\hline $0.18524199 \quad 1$ & 1.0 \\
\hline \multicolumn{2}{|l|}{ p 11.0} \\
\hline $0.08442189 \quad 1$ & 1.0 \\
\hline \multicolumn{2}{|l|}{ d 11.0} \\
\hline 6.1935321 & 1.0 \\
\hline \multicolumn{2}{|l|}{ d 11.0} \\
\hline 2.40212171 & 1.0 \\
\hline \multicolumn{2}{|l|}{ d 11.0} \\
\hline 1.03170412 & 1.0 \\
\hline \multicolumn{2}{|l|}{ d 11.0} \\
\hline 0.382063153 & 1.0 \\
\hline \multicolumn{2}{|l|}{ f 11.0} \\
\hline 3.71172512 & 1.0 \\
\hline \multicolumn{2}{|l|}{ f 11.0} \\
\hline 1.5504877 & 1.0 \\
\hline \multicolumn{2}{|l|}{ f 11.0} \\
\hline 0.59175402 & 1.0 \\
\hline \multicolumn{2}{|l|}{ g 11.0} \\
\hline 3.34033282 & 1.0 \\
\hline g 11.0 & \\
\hline 1.18999892 & 1.0 \\
\hline
\end{tabular}




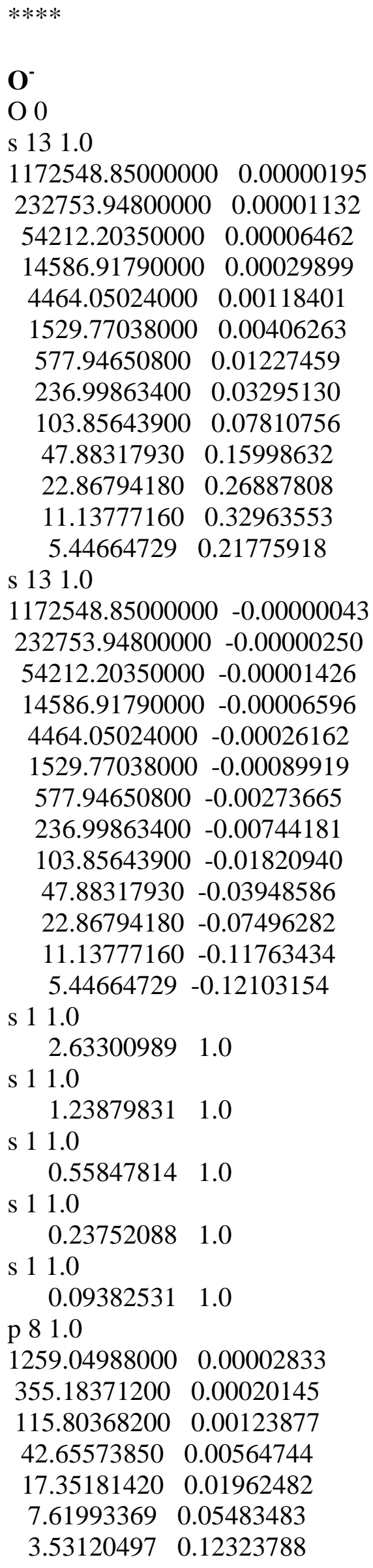




\begin{tabular}{|c|c|}
\hline \multirow{2}{*}{\multicolumn{2}{|c|}{$\begin{aligned} & 1.688055210 .20848673 \\
\text { p } 11.0 & \end{aligned}$}} \\
\hline & \\
\hline 0.81370860 & 1.0 \\
\hline p 11.0 & \\
\hline 0.38663063 & 1.0 \\
\hline p 11.0 & \\
\hline 0.17700896 & 1.0 \\
\hline p 11.0 & \\
\hline 0.07632950 & 1.0 \\
\hline p 11.0 & \\
\hline 0.03030501 & 1.0 \\
\hline d 11.0 & \\
\hline 4.53143433 & 1.0 \\
\hline d 11.0 & \\
\hline 1.70938879 & 1.0 \\
\hline d 11.0 & \\
\hline 0.69692929 & 1.0 \\
\hline d 11.0 & \\
\hline 0.23027054 & 1.0 \\
\hline f 11.0 & \\
\hline 3.51499215 & 1.0 \\
\hline f 11.0 & \\
\hline 1.3621268 & 1.0 \\
\hline f 11.0 & \\
\hline 0.479688053 & 1.0 \\
\hline g 11.0 & \\
\hline 2.8891314 & 1.0 \\
\hline g 11.0 & \\
\hline 0.954012189 & 1.0 \\
\hline
\end{tabular}

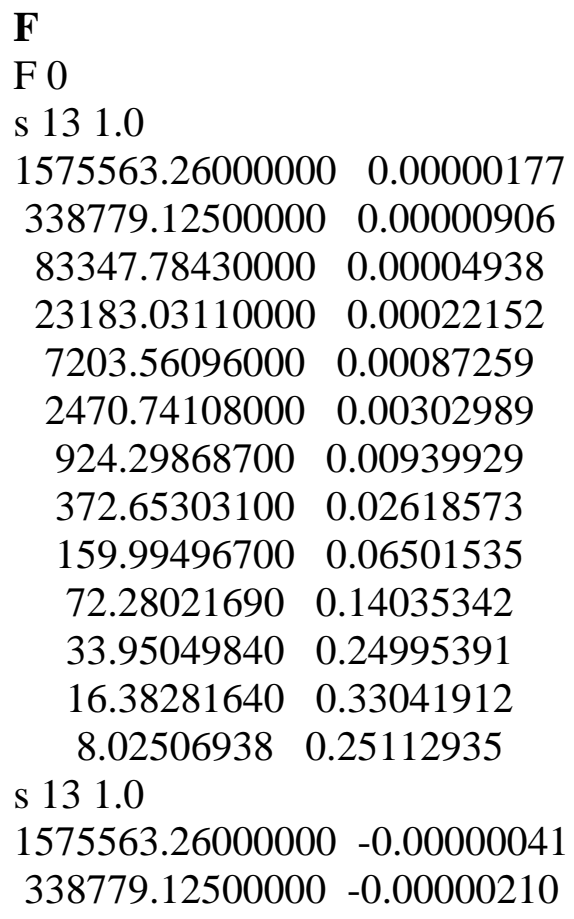




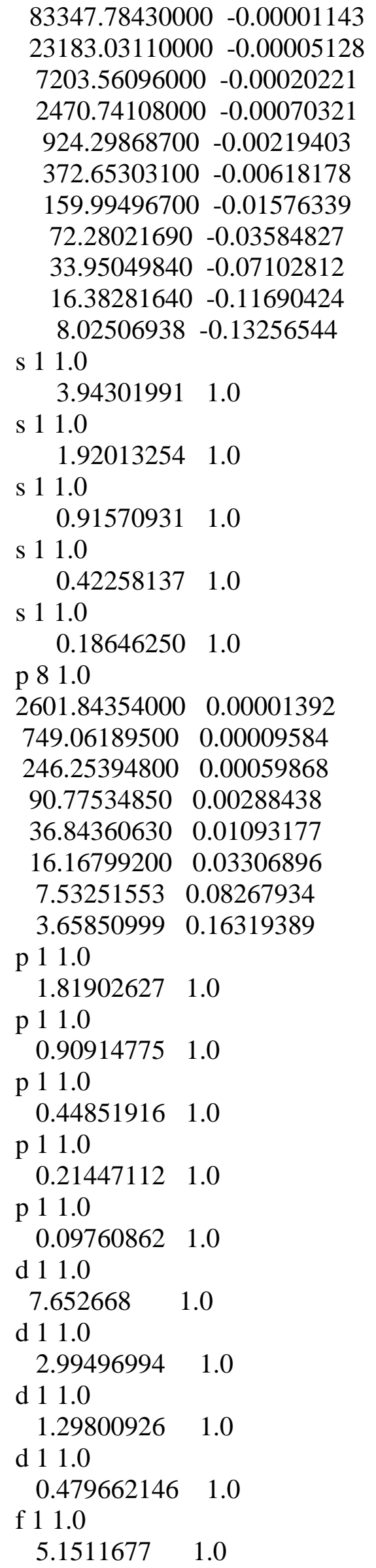



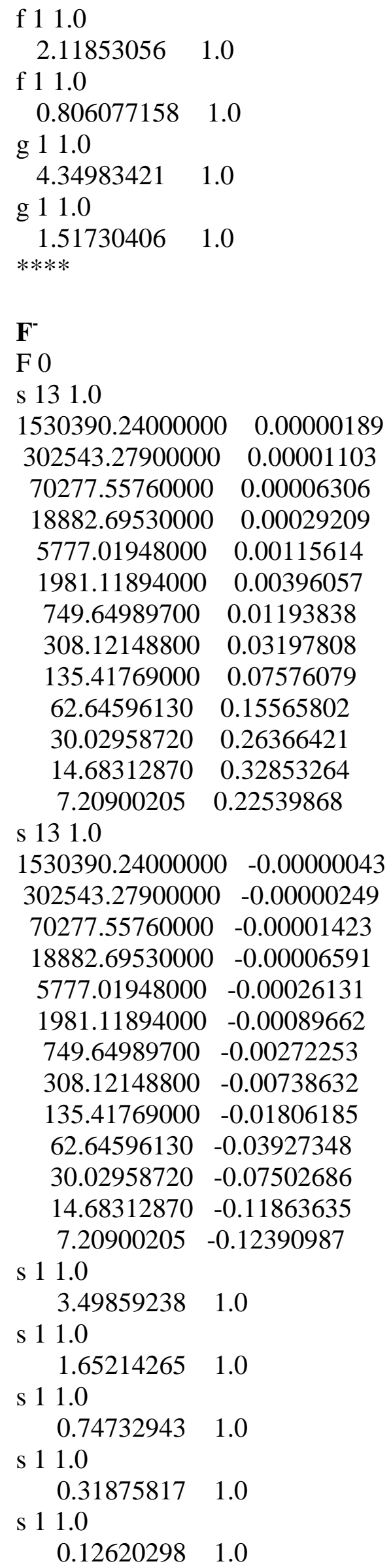


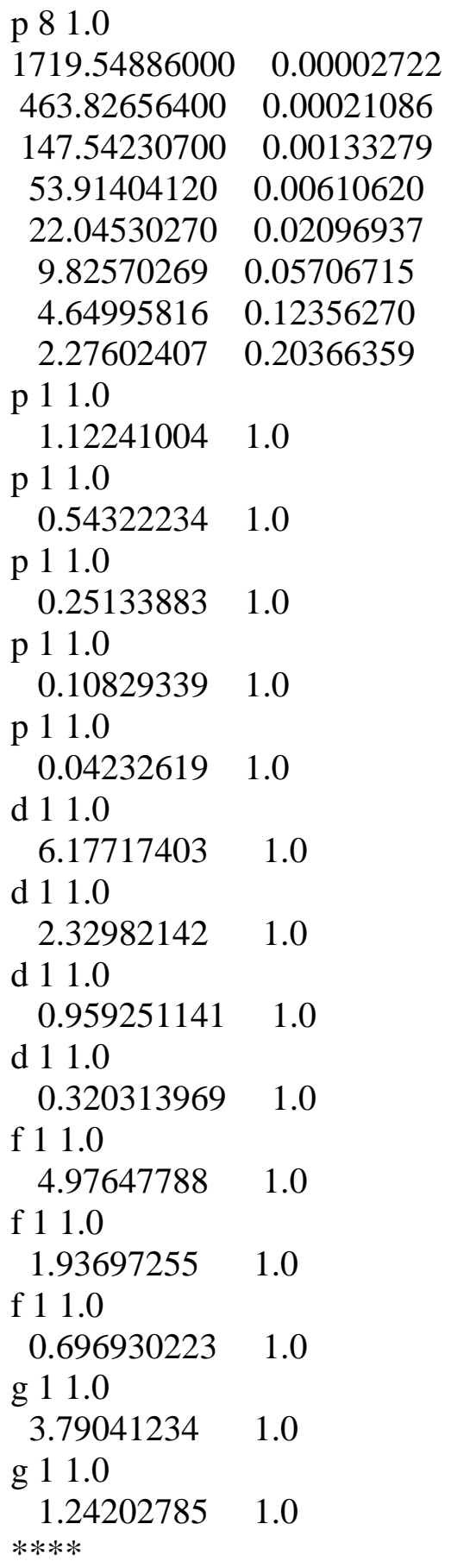

Expoentes de polarização $4 d 3 f 2 g 1 h$

\section{B}

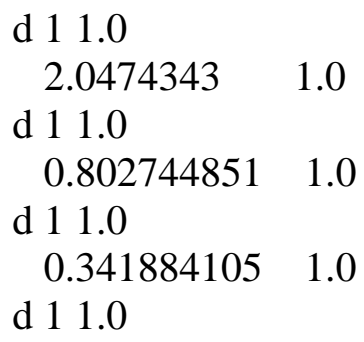




\begin{tabular}{|c|c|}
\hline \multirow{2}{*}{\multicolumn{2}{|c|}{$\begin{array}{r}1.8487 \\
\text { f } 11.0\end{array}$}} \\
\hline & \\
\hline 0.861451599 & 1.0 \\
\hline f 11.0 & \\
\hline 0.351867616 & 1.0 \\
\hline g 11.0 & \\
\hline 1.70307572 & 1.0 \\
\hline g 11.0 & \\
\hline 0.696717196 & 1.0 \\
\hline h 11.0 & \\
\hline $\begin{array}{l}1.25423421 \\
* * *\end{array}$ & \\
\hline
\end{tabular}

$\mathbf{C}^{-}$

d 11.0

$2.16643247 \quad 1.0$

d 11.0

$0.836882878 \quad 1.0$

d 11.0

$0.342947617 \quad 1.0$

d 11.0

0.1168919241 .0

f 11.0

$1.62622553 \quad 1.0$

f 11.0

$0.67216567 \quad 1.0$

f 11.0

$0.247468756 \quad 1.0$

g 11.0

$1.46706112 \quad 1.0$

g 11.0

$0.540216394 \quad 1.0$

h 11.0

$1.06418975 \quad 1.0$

$* * * *$

O
d 11.0
$6.18050871 \quad 1.0$
d 11.0
$2.4049759 \quad 1.0$
d 11.0
$1.03142661 \quad 1.0$
d 11.0
$0.381638551 \quad 1.0$
f 11.0
$3.72893494 \quad 1.0$
f 11.0 


\begin{tabular}{|c|c|}
\hline 1.56729489 & 1.0 \\
\hline f 11.0 & \\
\hline 0.598104993 & 1.0 \\
\hline g 11.0 & \\
\hline 3.24531325 & 10 \\
\hline g 11.0 & \\
\hline 1.20167845 & \\
\hline h 11.0 & \\
\hline 2.32819332 & \\
\hline
\end{tabular}

$\mathbf{O}^{-}$

d 11.0

$4.51768161 \quad 1.0$

d 11.0

$1.71003153 \quad 1.0$

d 11.0

$0.696292985 \quad 1.0$

d 11.0

$0.230315361 \quad 1.0$

f 11.0

$3.5442579 \quad 1.0$

f 11.0

$1.37686824 \quad 1.0$

f 11.0

$0.48396939 \quad 1.0$

g 11.0

$2.77555096 \quad 1.0$

g 11.0

$0.945946975 \quad 1.0$

h 11.0

$2.04531193 \quad 1.0$

$* * * *$

F

d 11.0

$\begin{array}{ll}7.64667823 & 1.0\end{array}$

d 11.0

$2.98974812 \quad 1.0$

d 11.0

$1.29200357 \quad 1.0$

d 11.0

$0.478318575 \quad 1.0$

f 11.0

$5.20770958 \quad 1.0$

f 11.0

$2.13818518 \quad 1.0$

f 11.0 


\begin{tabular}{|c|c|}
\hline 0.80905229 & 1.0 \\
\hline g 11.0 & \\
\hline 4.23001341 & 1.0 \\
\hline g 11.0 & \\
\hline 1.52726617 & 1.0 \\
\hline h 11.0 & \\
\hline $\begin{array}{l}2.9955526 \\
* * * *\end{array}$ & 1.0 \\
\hline
\end{tabular}

$\mathbf{F}^{-}$

d 11.0

$6.15103161 \quad 1.0$

d 11.0

$2.32465486 \quad 1.0$

d 11.0

$0.954897149 \quad 1.0$

d 11.0

$0.319631204 \quad 1.0$

f 11.0

$5.05546303 \quad 1.0$

f 11.0

$1.96366321 \quad 1.0$

f 11.0

$0.706557204 \quad 1.0$

g 11.0

$3.65144895 \quad 1.0$

g 11.0

$1.23618448 \quad 1.0$

h 11.0

$2.70608179 \quad 1.0$ 